\title{
Long-range pollution transport during the MILAGRO-2006 campaign: a case study of a major Mexico City outflow event using free-floating altitude-controlled balloons
}

\author{
P. B. Voss ${ }^{1}$, R. A. Zaveri ${ }^{2}$, F. M. Flocke ${ }^{3}$, H. Mao ${ }^{4}$, T. P. Hartley ${ }^{1}$, P. DeAmicis ${ }^{1}$, I. Deonandan ${ }^{1}$, G. Contreras-Jiménez ${ }^{5}$, \\ O. Martínez-Antonio ${ }^{5}$, M. Figueroa Estrada ${ }^{6}$, D. Greenberg ${ }^{7}$, T. L. Campos $^{3}$, A. J. Weinheimer ${ }^{3}$, D. J. Knapp ${ }^{3}$,

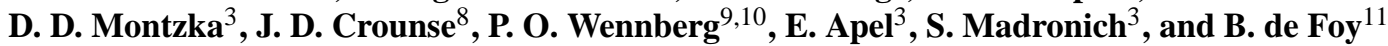 \\ ${ }^{1}$ Picker Engineering Program, Smith College, Northampton, MA, USA \\ ${ }^{2}$ Pacific Northwest National Laboratory, Richland, WA, USA \\ ${ }^{3}$ National Center for Atmospheric Research, Boulder, CO, USA \\ ${ }^{4}$ Institute for the Study of Earth, Oceans, and Space, University of New Hampshire, Durham, NH, USA \\ ${ }^{5}$ Centro de Investigaciones Químicas, Universidad Autónoma del Estado de Morelos, Cuernavaca, Mexico \\ ${ }^{6}$ Instituto Nacional de Ecologia, Delegación Coyoacán, México D.F., Mexico \\ ${ }^{7}$ Mohawk Trail Regional School District, Shelburne Falls, MA, USA \\ ${ }^{8}$ Division of Chemistry and Chemical Engineering, California Institute of Technology, Pasadena, CA, USA \\ ${ }^{9}$ Division of Engineering and Applied Science and Geological Science and Planetary Science, California Institute of \\ Technology, Pasadena, CA, USA \\ ${ }^{10}$ Division of Geological and Planetary Sciences, California Institute of Technology, Pasadena, CA, USA \\ ${ }^{11}$ Department of Earth and Atmospheric Sciences, Saint Louis University, St. Louis, MO, USA
}

Received: 22 January 2010 - Published in Atmos. Chem. Phys. Discuss.: 9 February 2010

Revised: 28 June 2010 - Accepted: 16 July 2010 - Published: 4 August 2010

\begin{abstract}
One of the major objectives of the Megacities Initiative: Local And Global Research Observations (MILAGRO-2006) campaign was to investigate the longrange transport of polluted Mexico City Metropolitan Area (MCMA) outflow and determine its downwind impacts on air quality and climate. Six research aircraft, including the National Center for Atmospheric Research (NCAR) C-130, made extensive chemical, aerosol, and radiation measurements above MCMA and more than $1000 \mathrm{~km}$ downwind in order to characterize the evolution of the outflow as it aged and dispersed over the Mesa Alta, Sierra Madre Oriental, Coastal Plain, and Gulf of Mexico. As part of this effort, free-floating Controlled-Meteorological (CMET) balloons, commanded to change altitude via satellite, made repeated profile measurements of winds and state variables within the advecting outflow. In this paper, we present an analysis of the data from two CMET balloons that were launched near Mexico City on the afternoon of 18 March 2006 and floated downwind with the MCMA pollution for nearly $30 \mathrm{~h}$. The repeating profile measurements show the evolving structure
\end{abstract}

Correspondence to: P. B. Voss (pvoss@ smith.edu) of the outflow in considerable detail: its stability and stratification, interaction with other air masses, mixing episodes, and dispersion into the regional background. Air parcel trajectories, computed directly from the balloon wind profiles, show three transport pathways on 18-19 March: (a) highaltitude advection of the top of the MCMA mixed layer, (b) mid-level outflow over the Sierra Madre Oriental followed by decoupling and isolated transport over the Gulf of Mexico, and (c) low-level outflow with entrainment into a cleaner northwesterly jet above the Coastal Plain. The C130 aircraft intercepted the balloon-based trajectories three times on 19 March, once along each of these pathways; in all three cases, peaks in urban tracer concentrations and LIDAR backscatter are consistent with MCMA pollution. In comparison with the transport models used in the campaign, the balloon-based trajectories appear to shear the outflow far more uniformly and decouple it from the surface, thus forming a thin but expansive polluted layer over the Gulf of Mexico that is well aligned with the aircraft observations. These results provide critical context for the extensive aircraft measurements made during the 18-19 March MCMA outflow event and may have broader implications for modelling and understanding long-range transport. 


\section{Introduction}

Over the past half century, the world's megacities have grown at a phenomenal pace. These sprawling urban regions, defined as having more than 10 million inhabitants, have grown in both number and size due to the world's rising population and the compounding effect of rural-to-urban demographic shifts. Whereas New York was the only megacity in 1950, there are now more than 22 such urban amalgamations. The Mexico City Metropolitan Area (MCMA), the subject of the present study, is the second largest megacity in the world with approximately 20 million inhabitants, 3.5 million vehicles, and 40000 industries (Molina et al., 2007)

Air quality within and around these growing megacities is an issue of serious public concern. High concentrations of heavy metals, particulates, acids, and reactive gasses are well known to adversely affect human health (e.g., Holguín et al., 2003; Dockery et al., 1993; Pope et al., 2009), agricultural productivity (Chameides et al., 1999; Reilly et al., 2007), and ecosystem function (de Lourdes de Bauer and HernandezTejeda, 2007; Felzer et al., 2007; Sitch et al., 2007). Within the MCMA basin, pervasive air pollution can be attributed to the large number of local sources, to surrounding mountains that inhibit ventilation, and to intense sunlight that accelerates photochemical ozone production. Due in part to this unfortunate situation, Mexico City has gained international stature as a center for atmospheric research. Several major studies, most recently the Mexico City Metropolitan Area (MCMA) campaign in 2003, have sought to better understand the sources, sinks, circulation, and transformation of pollutants in the basin (Molina et al., 2007). These studies have helped inform policy decisions that have improved air quality in Mexico City even as its population has continued to grow (Molina and Molina, 2002).

While air pollution chemistry and transport within the basin are now reasonably well understood, comparatively little is known about the downwind impacts of MCMA pollution. How far do the airborne aerosols, acids, and reactive gasses travel? How are these pollutants transformed and dispersed into the regional background, and what are their ultimate fates? How do these pollutants impact the composition of the regional atmosphere and surface air quality at locations downwind? Are pollutants from MCMA sufficiently concentrated to affect the regional radiation budget (Jáuregui and Luyando, 1999; Raga et al., 2001), agricultural productivity (Chameides, 1999), and precipitation patterns (Jáuregui and Romales, 1996)?

The Megacities Initiative: Local And Global Research Observations (MILAGRO) field campaign in March 2006 was organized to address these questions by bringing together an extensive suite of measurements from research aircraft, satellites, mobile platforms, and ground stations (Molina et al., 2010). A major goal of the field campaign was to characterize the air in the MCMA basin and then observe its evolution as it was transported downwind. The month of March was chosen for the field campaign because of the prevalence of the dry sunny weather (Jáuregui, 2000) and the northeastward transport that occurs $20-30 \%$ of the time at that time of year (Fast et al., 2007; de Foy et al., 2008). The focus on northeastward transport permitted the development of three research supersites (T0, T1, and T2) along this axis (Doran et al., 2007) and allowed for the extensive planning needed to coordinate the MILAGRO aircraft with each other, with the surfaces sites, and with satellite overpasses during transport events.

To support the goals of the MILAGRO campaign, our group contributed newly developed Controlled Meteorological (CMET) balloons to measure trajectories and evolving state parameters during long-range transport events (Voss et al., 2005, 2009). Similar free-floating balloons have been used for many years to characterize transport and measure trajectories (e.g., Lally, 1967; Banta, 1976; Zak, 1983; Malaterre, 1993; Knudsen and Carver, 1994; Stohl, 1998; Businger et al., 1999; Johnson et al., 2000; Riddle et al., 2006; Mao et al., 2006; Zaveri et al., 2010a, b). These efforts have generally focused on tracking the horizontal motion of air masses or equivalently volumes of air that are sufficiently large to maintain their physical and chemical identity over a time period of interest. The CMET balloons, with their highly efficient altitude control, enable a new methodology for studying transport. Rather than drifting with an air mass at one altitude, they can perform repeated soundings to quantify the evolving vertical structure of the atmosphere. The resulting profiles of winds, thermal stability, and specific humidity allow them to track an air mass at multiple altitudes and, at the same time, reveal how it is being mixed, sheared, and dispersed into the regional background. Figure 1 provides a brief overview of the CMET balloon flights and introduces some of the terminology used in this paper.

The principal objectives of the CMET balloon study during MILAGRO were to (a) observe directly the transport trajectories, vertical mixing, and horizontal dispersion of the MCMA plume during major northeastward outflow events, (b) characterize the coherence and terrain-following tendency of the outflow, (c) help guide MILAGRO research aircraft to the aged MCMA emissions over the Gulf of Mexico, and (d) provide a comprehensive set of in situ meteorological observations for assessing the accuracy of regional transport models during intensive study periods. This work contributes to a companion study of the photochemistry during transport (Zaveri et al., 2008) and is relevant to the many other transport and transformation studies undertaken during the MILAGRO campaign (e.g., Apel et al., 2010; Subramanian et al., 2010). 


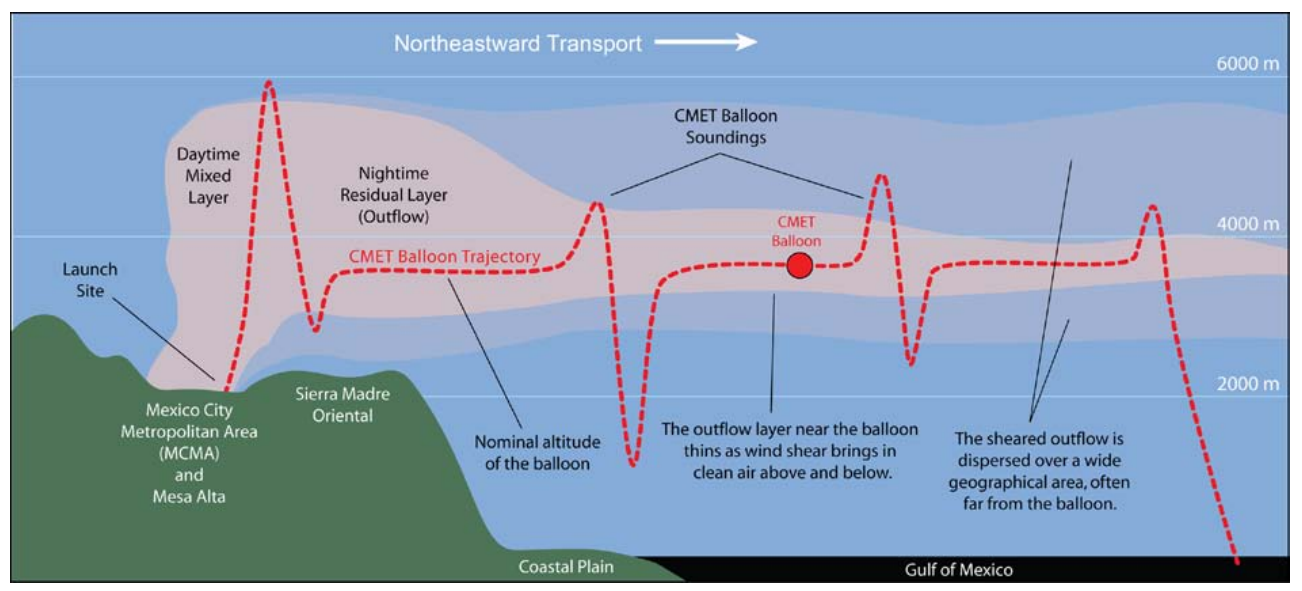

Fig. 1. Summary of the CMET balloon operational strategy during the MILAGRO campaign. Balloons were launched from MCMA into the polluted residual layer in the late afternoon and then commanded to perform repeated soundings as they drifted downwind with the outflow for almost $30 \mathrm{~h}$. Generally the balloons were flown in pairs with one performing deep soundings and the other operated more conservatively and in closer proximity to the outflow layer being tracked.
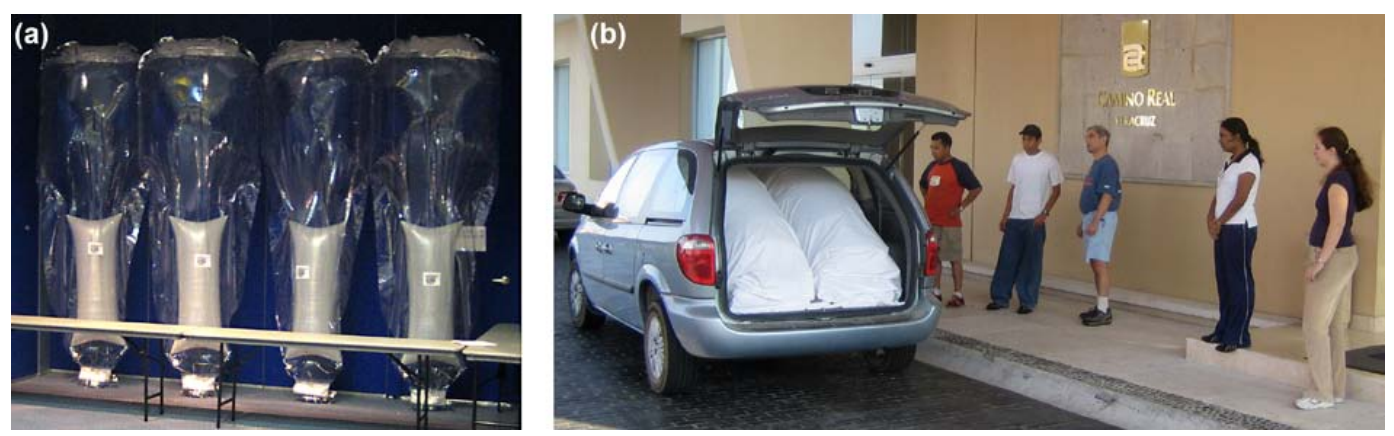

Fig. 2. (a) Four CMET balloons being ballasted at the MILAGRO Aircraft Operations Center in Veracruz. (b) Two of the balloons packed into a minivan for transport to Mexico City. The balloons were launched into the areas of highest pollution as determined by models and by observations from aircraft, satellites, ground stations, and the launch team. Four undergraduate science and engineering students from Mexico and the United States and a k-12 teacher, in the photo at right, contributed to the CMET balloon study.

\section{Experimental}

In this section we describe the CMET balloons, their deployment during the MILAGRO campaign, and details of the research aircraft, surface stations, and transport models that are relevant to our analysis.

\subsection{CMET balloons}

Controlled Meteorological (CMET) balloons are small altitude-controlled platforms with bi-directional satellite communication and long-duration flight capability (Voss et al., 2009). Their relatively compact size $(0.9 \mathrm{~m}$ in diameter and $3.2 \mathrm{~m}$ tall) allows them to be transported via minivan and launched into targeted pollution events (Fig. 2). Once airborne, the balloons drift with the horizontal winds and can be commanded to perform repeated vertical soundings (e.g., Fig. 1). For the safety of the air traffic in and around Mexico
City, balloon flights were closely coordinated with Mexico's aviation authority, Servicios a la Navegación en el Espacio Aéreo Mexicano (SENEAM).

Each CMET balloon carried a 400-gram payload and measured horizontal winds, pressure, temperature, and relative humidity. The payload included an aspirated temperature and humidity sensor (General Electric NTC MC65 bead thermistor, $\pm 0.2^{\circ} \mathrm{C}$ and Vaisala model $17204 \mathrm{HM}, \pm 5 \% \mathrm{RH}$, $\pm 1^{\circ} \mathrm{C}$ ), a satellite modem (Iridium model A3LA-I), and a custom-built pump/valve system for altitude control. Power was provided by a thin-film photovoltaic panel (PowerFilm MPT6- $150 \times 6,400 \mathrm{~mA}$ at $18 \mathrm{~V}$ ) coupled with a lithium polymer battery array (Batteries America, $1450 \mathrm{mAh}$ at $16.8 \mathrm{~V}$ ). Position was measured by a GPS receiver (Synergy Systems model $\mathrm{M} 12+, \pm 5 \mathrm{~m}$ horizontal, $\pm 50 \mathrm{~m}$ vertical) with short-term vertical resolution increased to $\pm 1.0 \mathrm{~m}$ by a pressure altimeter (Motorola model MPX 5100AP, $\pm 25 \mathrm{mb}$ specified accuracy, $0.035 \mathrm{mb}$ bit resolution). Measurements were 
made at 15 -s and 30-s intervals during soundings and at 60-s intervals during float. An in-flight comparison, discussed in Sect. 3.1, shows that the meteorological measurements made by the CMET balloons and those made by the research aircraft are in good agreement.

Twelve CMET balloons along with the necessary supporting equipment were transported into Mexico as carry-on luggage on a commercial flight. This arrangement eliminated the delays and potential damage that can occur with customs inspections at larger shipping centers. The balloons were prepared, ballasted, and controlled from the MILAGRO Aircraft Operations Center at the Hotel Camino Real in Veracruz in order to facilitate coordination with the modeling teams, aircraft operators, and mission scientists.

\subsection{MILAGRO aircraft}

Six research aircraft supported the MILAGRO campaign (Singh et al., 2009; Yokelson et al., 2007). The aircraft were instrumented for a range of purposes and included the USDA Forest Service Twin Otter (biomass burning), the DOE G-1 and NASA B200 (MCMA basin photochemistry and transport), the NSF/NCAR C-130 (regional photochemistry and transport), the NASA J-31 (clouds and aerosols), and NASA DC-8 (photochemistry, aerosols, and long-range transport). The National Science Foundation/National Center for Atmospheric Research (NSF/NCAR) C-130 in particular had a comprehensive instrument package and regional range that was well matched to the $1000-\mathrm{km} 24-\mathrm{h}$ transport events characterized by the CMET balloons.

As configured during the MILAGRO campaign, the NSF/NCAR C-130 Hercules aircraft (hereafter C-130) measured approximately 100 chemical species including $\mathrm{CO}$, $\mathrm{CO}_{2}, \mathrm{O}_{3}, \mathrm{NO}, \mathrm{NO}_{2}, \mathrm{HNO}_{3}, \mathrm{PAN}, \mathrm{OH}, \mathrm{HO}_{2}, \mathrm{RO}_{2}$, and VOCs, aerosol size, distribution, and composition, complete meteorological parameters, photolysis rates, and radiance. This comprehensive suite of instruments is well suited for addressing questions pertaining to the transport and transformation of tropospheric trace gasses and aerosols.

In this paper, we use five chemical measurements from the C-130 to help identify MCMA outflow. Hydrogen Cyanide $(\mathrm{HCN})$, an indicator of biomass burning, was measured by the California Institute of Technology Chemical Ionization Mass Spectrometer (CIMS). This measurement was carried out in air using the reagent ion $\mathrm{CF}_{3} \mathrm{O}$ - and monitoring for the cluster ion $\mathrm{CF}_{3} \mathrm{O}-\mathrm{HCN}$. The detection limit was $15 \mathrm{pptv}$ with a 0.5 -s integration time for $\mathrm{H}_{2} \mathrm{O}$ mixing ratios $<0.004$ (Crounse et al., 2006, 2009).

The other measurements $\left(\mathrm{CO}, \mathrm{NO}_{\mathrm{y}}, \mathrm{O}_{3}\right.$, and MTBE) were obtained by three instruments operated under the auspices of NCAR and NSF. CO was measured by a vacuum-ultraviolet resonance fluorescence instrument (Aero-Laser) similar to that described by Gerbig et al. (1999). The CO measurement had a precision of $3 \mathrm{ppbv}$, a resolution of $1 \mathrm{~s}$, and a typical accuracy of $\pm 10 \%$.
Ozone $\left(\mathrm{O}_{3}\right)$ was measured at $1 \mathrm{~Hz}$ with a detection limit of $\sim 0.02 \mathrm{ppbv}$ and an accuracy of $4 \%$ using the chemiluminescence technique with $\mathrm{NO}$ as the excess reagent. Total reactive nitrogen $\left(\mathrm{NO}_{\mathrm{y}}\right)$ was measured by heated Au-catalyzed conversion to $\mathrm{NO}$ (using $\mathrm{CO}$ as the reducing agent) and subsequent detection by chemiluminescence using $\mathrm{O}_{3}$ as the excess reagent. $\mathrm{NO}_{\mathrm{y}}$ was measured at $1 \mathrm{~Hz}$ with a 1 -s detection limit of $\sim 20$ pptv (Ridley et al., 1994).

Methyl tertiary-butyl ether (MTBE), an oxygenating additive in gasoline that is often used as an urban tracer, was measured by the Trace Organic Gas Analyzer (TOGA). This instrument, which uses a gas chromatograph and mass spectrometer (Agilent 5973) with cryogenic preconcentration, was operated by NCAR and NSF-supported investigators during MILAGRO. In-flight calibrations were carried out using a gravimetrically prepared mixture diluted dynamically to typical ambient mixing ratios (Apel et al., 2003, 2007).

As described in the C-130 Investigator Handbook (http: //www.eol.ucar.edu/instrumentation), relative humidity (RH) was measured by chilled mirror hygrometer (Buck 1011C). Ambient air temperature was measured by a platinum resistance thermometer (Rosemount Inc. 102E2AL, $\pm 0.5^{\circ} \mathrm{C}$ ), and ambient (static) pressure was measured using a DigiQuartz transducer (Paroscientific 1000, $\pm 0.3 \mathrm{mb}$ ). Horizontal winds were measured by a Radome gust probe $\left( \pm 0.5 \mathrm{~m} \mathrm{~s}^{-1}\right)$. An NCAR-designed Scanning Aerosol Backscatter LIDAR (SABL), operating at $532 \mathrm{~nm}$ and $1064 \mathrm{~nm}$, provided critical information on aerosol structure above and below the aircraft (http://www.eol.ucar.edu/rsf/ sabl).

\subsection{Transport models}

During the MILAGRO field campaign, ten models ranging in scale from local to synoptic were used to predict the location of the MCMA outflow, simulate its chemical transformation, and aid in aircraft flight planning (Fast et al., 2007). These included the MM5 model (Grell et al., 1993) and the WRF model (Skamarock et al., 2005) in combination with chemical, tracer and trajectory models. The MM5-FLEXPART model (de Foy et al., 2006) was used extensively to plan the CMET balloon flights and determine the optimal times and locations for targeted launches in the MCMA basin.

The initial and boundary conditions for the operational models were derived from the National Centers for Environmental Prediction Global Forecasting System (NCEP/GFS) analyses. During the campaign, the GFS model assimilated data from additional rawinsondes launched four times daily from Acapulco, Mexico City, and Veracruz as well as from the regular once-daily launches from four sites distributed over central Mexico. Fast et al. (2007) found that the GFS wind directions at $500 \mathrm{hPa}$ agreed well with the assimilated rawinsonde data while wind speeds differed by as much as $5 \mathrm{~m} \mathrm{~s}^{-1}$ (up to $100 \%$ error). 
Table 1. MCMA CMET balloon launch sites during the MILAGRO campaign. The Texcoco site was approved only for a single launch. The distance listed in the far right column is measured from the MEX airport near the center of Mexico City.

\begin{tabular}{lccc}
\hline Town & $\begin{array}{c}\text { Map ID } \\
\text { (see Fig. 3) }\end{array}$ & $\begin{array}{c}\text { Location } \\
\text { (latitude, longitude) }\end{array}$ & $\begin{array}{c}\text { Distance to MEX } \\
(\mathrm{km})\end{array}$ \\
\hline Tepeji del Río & TEP & $19.890^{\circ} \mathrm{N}, 99.343^{\circ} \mathrm{W}$ & 58 \\
Tizayuca & TIZ & $19.892^{\circ} \mathrm{N}, 98.936^{\circ} \mathrm{W}$ & 52 \\
Teotihuacan & TEO & $19.680^{\circ} \mathrm{N}, 98.847^{\circ} \mathrm{W}$ & 36 \\
Texcoco & TEX & $19.489^{\circ} \mathrm{N}, 98.895^{\circ} \mathrm{W}$ & 19 \\
\hline
\end{tabular}

In this paper, we compare the CMET balloon trajectories with those from the regional WRF-FLEXPART model (Stohl et al., 2005; Doran et al., 2008). WRF-FLEXPART simulations of transport during the campaign were evaluated using surface, rawinsonde, and radar wind profiler data and were found to be representative of the pollutant transport within the MCMA basin (de Foy et al., 2009a).

When applied to regional transport, model errors can emerge from inaccuracies in the GFS boundary conditions and from nuances of terrain following, atmospheric stability, and vertical mixing, all of which influence transport and are difficult to parameterize. Some of these subtleties are highlighted later in the discussion of CMET balloon data from the major northeastward transport events on 11-12 March and 18-19 March.

\subsection{CMET balloon field operations}

On days when the operational models predicted northeastward outflow, CMET balloons were transported in pairs via minivan from Veracruz to Mexico City for targeted launches. Typically, departures occurred in the morning (14:00 UTC) with arrival in Mexico City by mid afternoon (21:00 UTC). In central Mexico during March, Universal Coordinated Time (UTC) leads the local Central Standard Time (CST) by $6 \mathrm{~h}$. Three designated launch sites and one opportunistic launch from Texcoco were approved by SENEAM (Table 1). These sites allowed the balloons to be launched on the most polluted downwind side of Mexico City under a wide range of wind conditions (Fig. 3).

Because of the complex circulation within the basin, the ideal launch site was often difficult to determine and was therefore selected during the final $1-2 \mathrm{~h}$ before launch using the most recent model forecasts, MILAGRO aircraft communications, and near-real-time data from the RAMA network and T1/T2 profilers (e.g., Sect. 3.2). The large scale of the MCMA plume and the uniformity of the winds aloft, however, ensured that our transport analysis was not dependent on the exact launch site; a simpler launch strategy could be employed in future studies.

The CMET balloons were released into the residual layer in the late afternoon or early evening (21:00-01:00 UTC) and

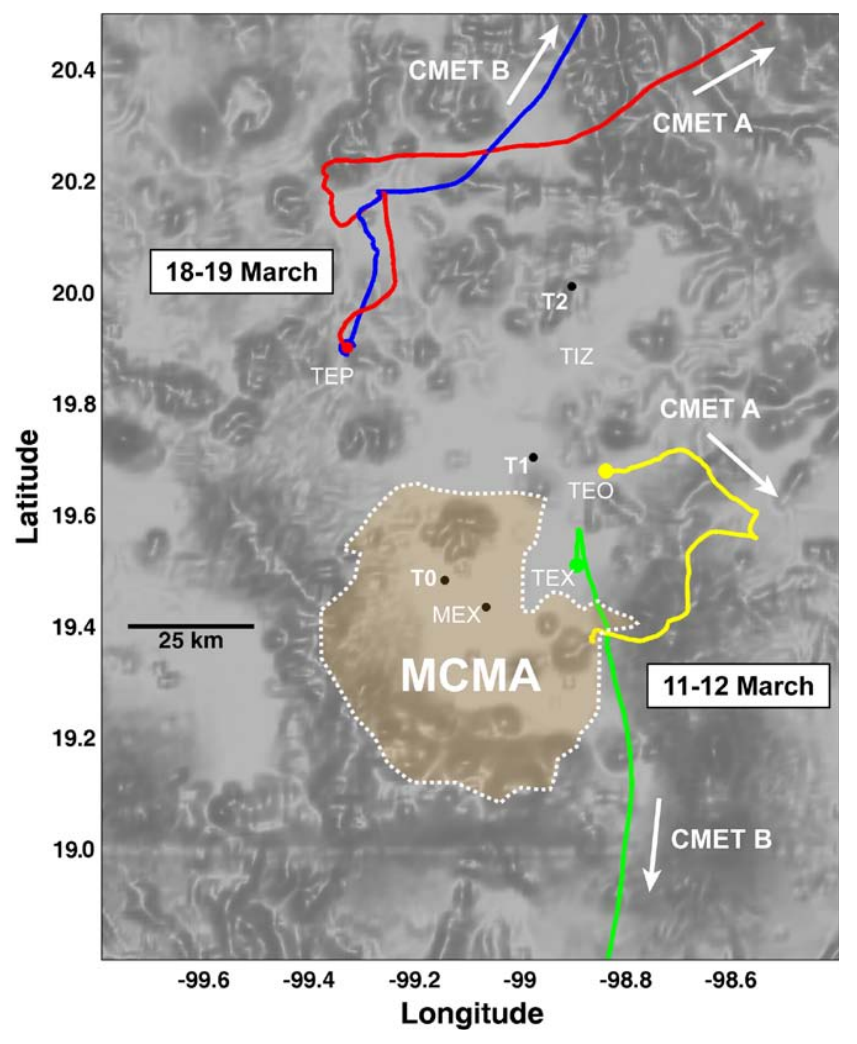

Fig. 3. Map of the Mexico City Metropolitan Area (MCMA) showing the research supersites (T0, T1, and T2), the approved CMET balloon launch sites (TEP, TIZ, TEQ, TEX), the Mexico City Airport (MEX), and the initial portions of the CMET balloon trajectories during two major MCMA outflow events (11-12 March and 18-19 March).

ascended at a rate of $2-3 \mathrm{~m} \mathrm{~s}^{-1}$. As shown in Fig. 1, the residual layer refers to the air that comprised the mixed layer during the day; it is characterized by initially uniform potential temperature, specific humidity, and pollutant mixing ratios (Stull, 2000). The approximate depth of the residual layer was determined using real-time data from the mission aircraft, T1/T2 profilers, and the CMET balloons. The balloons were typically commanded to stabilize at the mid-level altitude of the residual layer.

During the ensuing transport, the nominal float altitude of the balloons ranged from 3400-4500 m (initially 1200$1800 \mathrm{~m}$ a.g.l.) depending on residual layer depth at the time of launch and the need to avoid downwind terrain. Throughout this paper, altitude is always in meters above mean sea level (m.s.l.) unless specifically designated as above ground level (a.g.1.). Every few hours, the balloons were commanded (via satellite) to deviate from their nominal altitude in order to perform soundings. As described in Sect. 3.5, the resulting wind profiles allow trajectories to be computed over a range of altitudes. Our conclusions about transport are therefore largely independent of the nominal float altitude of the balloons. 
The initial phase of the MILAGRO balloon operation was devoted to field preparations, meetings with SENEAM officials, and a demonstration flight required for operation in MCMA airspace. The active part of the balloon study occurred during the period 7-22 March when conditions were amenable to northward transport and precipitation was minimal. During the $16 \mathrm{~d}$ available for the study, six CMET balloons were flown for a total $86.5 \mathrm{~h}$.

\subsection{Targeted MCMA outflow events}

The meteorology during the MILAGRO balloon study was characterized by two major outflow episodes (9-12 and 18-19 March) punctuated by Norte events on 14, 21, and 23 March (Fast et al., 2007). The successive Nortes, notable for their strong northerly winds (Mosino Aleman and Garcia, 1974), brought cleaner air and steadily increasing moisture to the Mesa Alta. By 22 March, the widespread convection and rain associated with this moisture ended the CMET balloon study.

\subsubsection{9-12 March outflow}

The first northeastward outflow event occurred during the period 9-12 March when a large and weakly organized synoptic high-pressure system was centered off the eastern coast of Florida. By 9 March, this system brought southwesterly winds aloft over central Mexico and northeastward transport of the MCMA pollution; the operational model consensus was for north and eastward transport to continue through midday on 12 March. A CMET balloon launched on 9 March into this outflow failed due to an altitude overshoot. Despite this setback, the C-130 successfully found the urban outflow to the northeast on 10 March, in good agreement with the model predictions.

On 11 March, two more CMET balloons were launched, one from Teotihuacan (21:40 UTC) and the other further south from Texcoco (00:47 UTC) where the air was visibly more polluted. The first balloon ascended to $4500 \mathrm{~m}$ and left the MCMA basin to the east. Three hours downwind, it turned $180^{\circ}$, reentered the basin headed for the Mexico City airport, and was terminated after $9.2 \mathrm{~h}$ in the air (Fig 3). The second balloon ascended to $4100 \mathrm{~m}$ (1800 m a.g.l.), headed due south out of the basin, and was terminated $150 \mathrm{~km}$ southwest of the city after $19.2 \mathrm{~h}$ aloft. These unexpected trajectories, which gave the CMET balloons their Spanish moniker "Los Globos Locos", showed that at least some of the pollution north and east of the city was reingested and then left the basin through the south gap in the late afternoon and evening of 11 March. Consistent with this scenario, the C-130 was unable to locate significant urban pollution northeast of the city on 12 March.

\subsubsection{8-19 March outflow}

A second major outflow event occurred during the period 1519 March as high pressure moved eastward across central Mexico and over the Gulf. By 18 March, the system was centered above the Yucatan Peninsula, generating southerly winds aloft over the MCMA basin (Fast et al., 2007). This synoptic forcing generated the characteristic outflow scenario in which polluted air from Mexico City became entrained in a deep convective boundary layer during the day ( $\sim 4 \mathrm{~km}$ a.g.l.) and was then transported northeastward out of the basin in the afternoon and evening. This overall transport scenario on 18-19 March was clearly evident in the $\mathrm{SO}_{2}$ signature at the surface as described in the basin-scale analysis by de Foy et al. (2009b). Nighttime drainage flow was seen to transport the plume from the Tula refinery complex north of the city southward into the MCMA basin on 17 March. In the early hours of 18 March, a wind shift brought the Popocatepetl volcanic plume over the city where it remained largely separate from the urban emissions as all pollution was flushed out of the basin to the north (de Foy et al., 2009b).

During the afternoon of 18 March, the DOE G-1 and the C-130 made extensive measurements of polluted air in the MCMA basin, fresh downwind emissions to the north, and cleaner air entering the basin from the south. Flight legs over the range of 3500-4000 m (1500-2000 m a.g.l.) included an east-west intercomparison over T2 (20:45-21:35 UTC) and multiple transects within the basin and along its southern edge (21:40-23:00 UTC).

As the aircraft were leaving the basin in the late afternoon, two CMET balloons were launched from Tepeji del Río: one at 22:30 UTC on 18 March and the other $1.5 \mathrm{~h}$ later at 00:00 UTC on 19 March (Fig. 3). The balloons ascended to their nominal float altitude of $3450 \mathrm{~m}$ with the first briefly overshooting and making a deep sounding to $6000 \mathrm{~m}$. By shortly after 00:00 UTC, the two balloons were travelling together at their nominal altitude over the Sierra Madre Oriental. Eleven hours later, as they drifted out over the Coastal Plain, they performed another set of deep soundings and then followed the coastline north over the Gulf of Mexico. Figure 4 shows the two balloon trajectories on 18-19 March (labelled CMET A and CMET B) in relation to the C-130 flight track on 19 March. The figure caption provides additional details about the balloon soundings and C-130 intercept locations. The balloons remained airborne for 29.5 and $24.8 \mathrm{~h}$ respectively, covered distances of 995 and $760 \mathrm{~km}$, and together performed more than 20 soundings; late in the flight, their locations were used to guide the $\mathrm{C}-130$ along a transect through the MCMA outflow. The remainder of this paper examines this transport event in detail. 


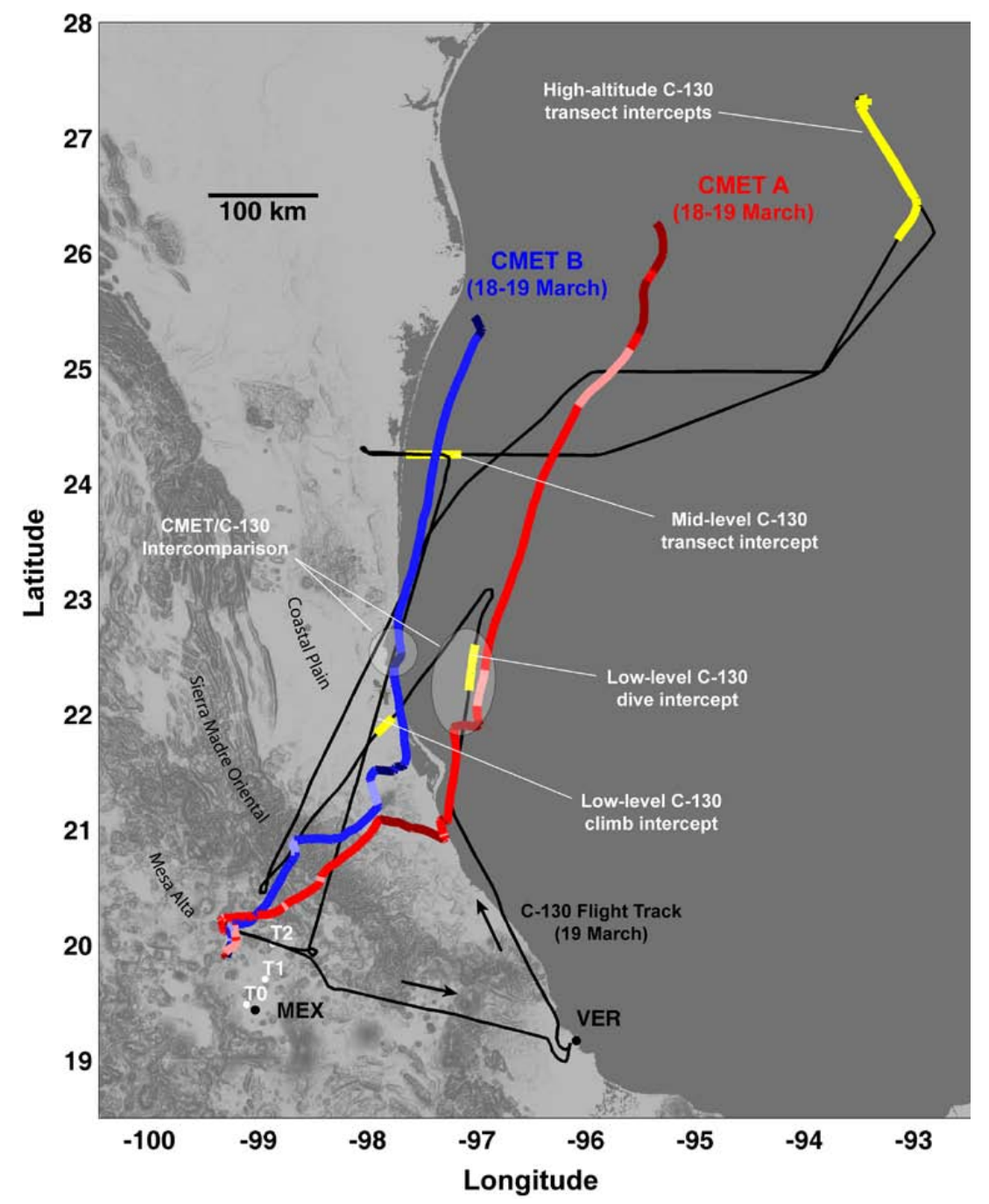

Fig. 4. Map showing, the trajectories of the two CMET balooons flown on 18-19 March (red and blue lines) and the C-130 flight track on 19 March (black line). MCMA is in the lower left. The balloons tracked a dispersing layer of polluted MCMA outflow that was sampled extensively by the C-130 near Mexico City and more than $1000 \mathrm{~km}$ downwind the following day. The dark segments of the balloon trajectories signify soundings substantially below the nominal float altitude of the balloons $(\sim 3450 \mathrm{~m})$ while light segments signify soundings above this level. The C-130 flight track is highlighted in yellow where it intercepts the MCMA balloon-based outflow trajectories (described in Sect. 3.5). The location of an opportunistic intercomparison between the CMET balloons and the C-130 aircraft is also shown. The Aircraft Operations Center in Veracruz (VER) is at the bottom of the map.

\section{Results and discussion}

The measurements made by the MILAGRO aircraft and two CMET balloons during 18-19 March are among the most extensive to date in a megacity outflow event. Using these data, we examine four phases of the MCMA outflow: wellmixed air exiting the basin, nighttime transport over the Sierra Madre Oriental, stratification above the Coastal Plain, and mixing over the Gulf of Mexico. The shear and stratification over the Coastal Plain split the outflow into two transport pathways, designated as low- and mid-level, which were both likely encountered by the C-130 on 19 March. A third pathway, high-altitude advection of the upper portion of the MCMA residual layer, was also tracked by the balloons and likely encountered by the C-130 on 19 March. The MCMA outflow that was transported along these three pathways was subjected to different conditions of temperature, humidity, and sunlight as it mixed to varying degrees with differing background air; the extensive chemical and aerosol observations made by the $\mathrm{C}-130$ during these encounters should therefore be useful in addressing the central questions of the MILAGRO campaign. 


\section{(a)}
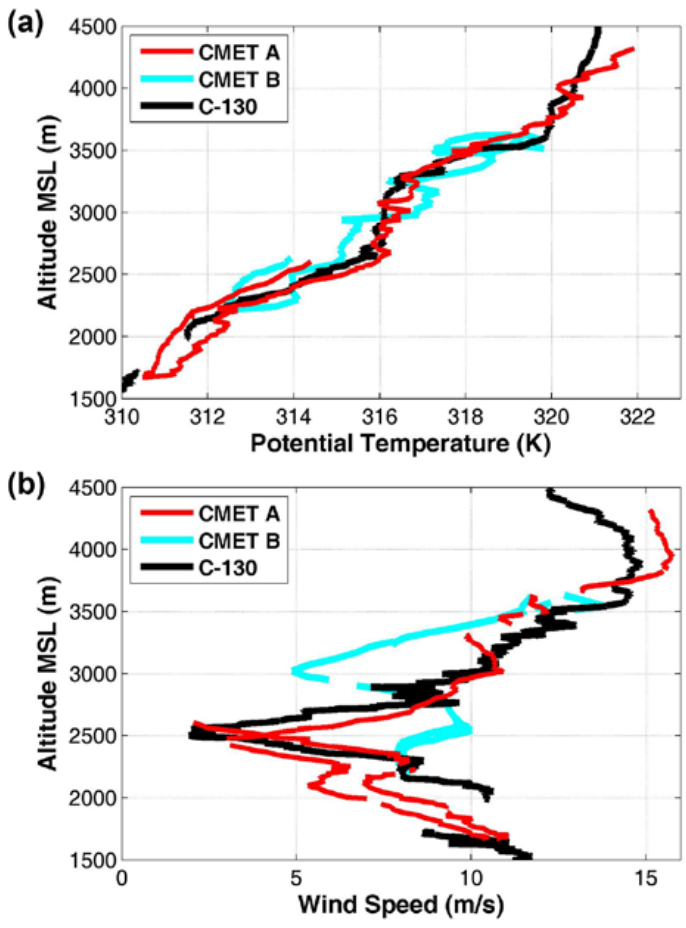
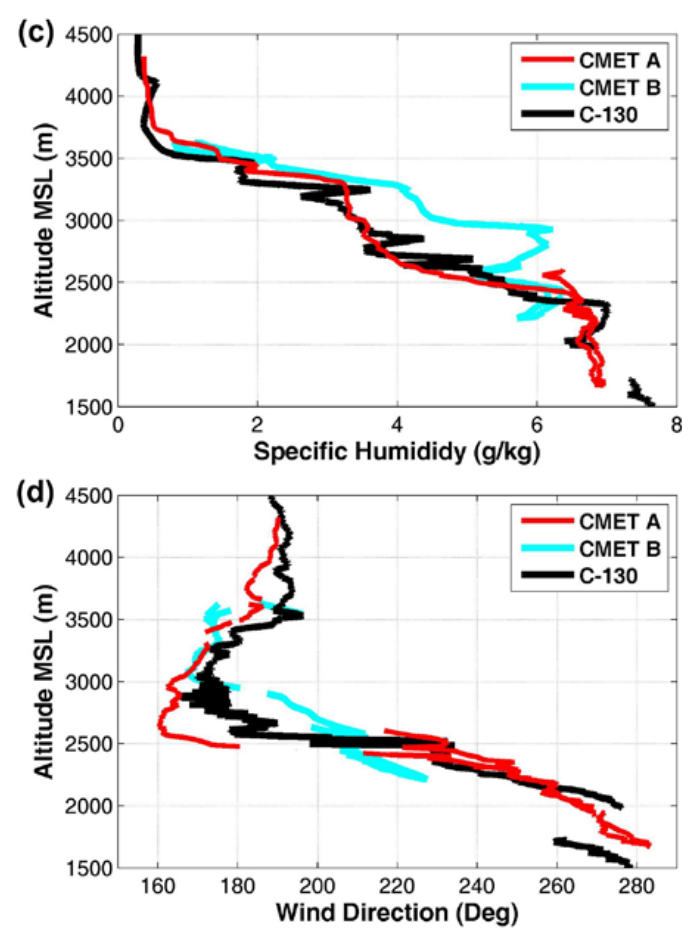

Fig. 5. Comparison of the CMET balloon and C-130 meteorological measurements over the altitude range $1500-4200 \mathrm{~m}$. Because the balloons were as far as $86 \mathrm{~km}$ away from the C-130 and $115 \mathrm{~km}$ from each other, differences among the measurements are largely the result of heterogeneity in the meteorological fields. Figure 4 shows the locations of the soundings used for the intercomparison.

\subsection{Flight validation of the balloon measurements}

Because our analysis is dependent on the accuracy of the CMET balloon observations, the results of an opportunistic intercomparison with the $\mathrm{C}-130$ are briefly discussed. This encounter occurred between 18:15-18:24 UTC on 19 March $\left(22.3^{\circ} \mathrm{N}, 97.1^{\circ} \mathrm{W}, 1500-4200 \mathrm{~m}\right)$ as the $\mathrm{C}-130$ was descending over the Gulf of Mexico and both CMET balloons were performing soundings (see Fig. 4). The balloons were a significant distance from each other $(115 \mathrm{~km})$ and from the C-130 (12-86 km for CMET A and 69-85 km for CMET B), so agreement to within the reported instrument accuracies (Sects. 2.1, 2.2) is not expected. However, as shown in Fig. 5, the agreement among all the measurements (temperature, specific humidity, and winds) over the full altitude range of the comparison is surprisingly good. The profiles measured by the different platforms do not differ systematically from each other and all show the same vertical structure. The largest differences occur among the profiles measured by the two identical balloons which are known to agree well with each other over the longer course of the flight. These results build confidence in the meteorological measurements and attest to the spatial uniformity of the meteorological fields, a critical assumption in our transport analysis.

\subsection{Initial conditions in the MCMA basin}

The daytime conditions within the basin on 18 March were typical of a high-pollution episode in Mexico City. By mid-morning, the air in the high-altitude $(2200 \mathrm{~m})$ basin was warming rapidly under intense sunlight and moderate southwesterly winds aloft $\left(5-10 \mathrm{~m} \mathrm{~s}^{-1}\right)$. Pollution entrained in the mixed layer (ML) was widely distributed across the north side of the basin (Fig 6a) as evident from the C-130 tracer measurements (Fig. 7a). The Micropulse LIDAR at the T1 supersite showed the ML growing from approximately $2 \mathrm{~km}$ a.g.l. at 18:00 UTC (noon) to nearly $4 \mathrm{~km}$ a.g.l. by 23:00 UTC. Infrared SABL imagery from the final C-130 flight leg at approximately 23:00 UTC (Fig. 8) shows the nascent residual layer extending across the city to altitudes exceeding $6 \mathrm{~km}$ ( $4 \mathrm{~km}$ a.g.l.).

Intense solar heating and weak synoptic forcing typically result in high mixing heights over the MCMA basin (Whiteman et al., 2000; de Foy et al., 2006; Doran et al., 2007). The mixing with very dry air aloft can associate MCMA pollution with low humidity. This can be seen in the pronounced anticorrelation between specific humidity and $\mathrm{CO}$ in the late afternoon on 18 March (compare Fig. $7 \mathrm{a}$ and $b$ ). The balloon measurements of specific humidity can therefore be used as an approximate tracer of the urban air, especially during the early portion of the flight. Furthermore, the relative humidity measured by the balloons was in the range 5-65\% 

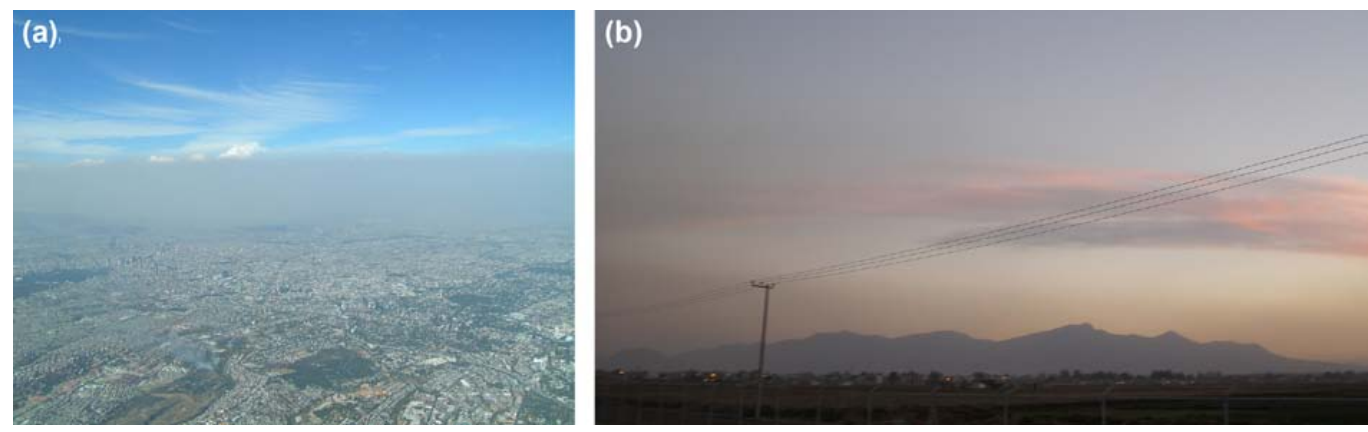

Fig. 6. (a) Air pollution obscures the entire north side of Mexico City in this photograph taken from the C-130 in the late afternoon of 18 March. The CMET balloons were launched at 22:30 UTC (the time of the photo) and 1.5 h later at 00:00 UTC (19 March) from a site in the background near the left edge of the image. Photo credit: S. Madronich. (b) The Sierra de Guadalupe mountain range near the center of the Mexico City was still enveloped in a polluted layer up to $1.5 \mathrm{~km}$ deep when this photograph was taken looking southeast at approximately 01:00 UTC (19 March).
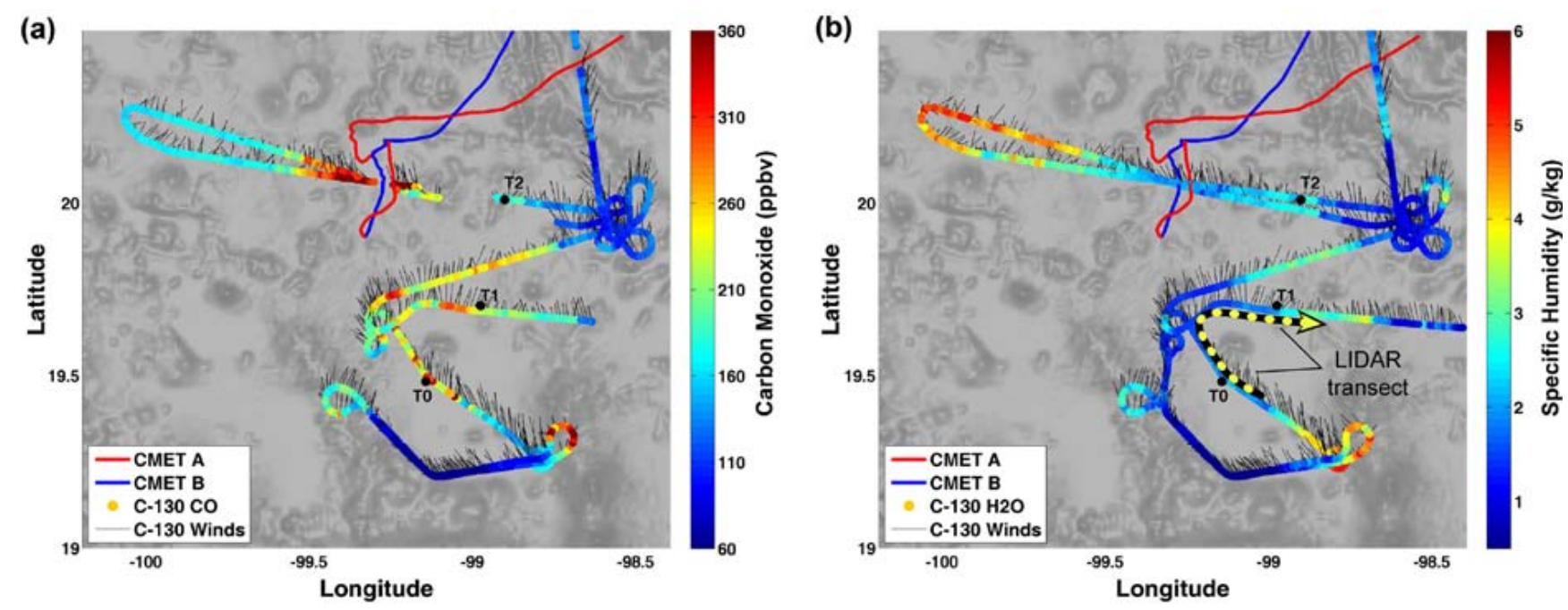

Fig. 7. (a) Carbon monoxide as measured by the C-130 during the afternoon of 18 March at altitudes ranging from 0-2 km a.g.1. The polluted air near T1, sampled at about 23:00 UTC, moved steadily north and was likely closely associated with the CMET balloons as they left the basin at approximately 00:00 UTC (see text). The barbs along the C-130 flight track show the observed winds converted to transport distance over a 15 min period. (b) Specific humidity was generally anticorrelated with pollution levels in the northwest quadrant of the city (i.e., dry air had elevated CO). This relationship allowed the balloon's humidity measurements to be used as a rough proxy for pollution levels, especially during the first several hours of flight. The dashed yellow line shows the approximate location of the LIDAR image in Fig. 8.

at all altitudes except in the marine boundary layer, an indication that non-condensing conditions prevailed throughout the transport event.

During the early evening, the balloon launch team observed that the air near Tepeji del Río became visibly more heterogeneous, likely as a result of drainage flows entering the basin and cleaner air arriving from the west (Fig. 6b). Despite this complex circulation, measurements made by the research aircraft, radar wind profilers at T1 and T2 (Fast et al., 2007), and CMET balloons all showed southerly flow above the basin surface during the afternoon and evening. The winds measured by the C-130 within the core of the pollution (near T0 and T1) were south-southwesterly, averaging $6.3 \mathrm{~m} \mathrm{~s}^{-1}$ at $173^{\circ}$. These winds would carry the MCMA daytime emissions just east of the launch site as the two CMET balloons were released 22:30 and 00:00 UTC respectively. The balloons thus marked the western side of the MCMA outflow that left the basin in the early evening.

\subsection{Nighttime transport over complex terrain}

During the night, the two CMET balloons tracked the MCMA outflow as it passed north and then turned northeast over the Sierra Madre Oriental. Repeated shallow soundings 


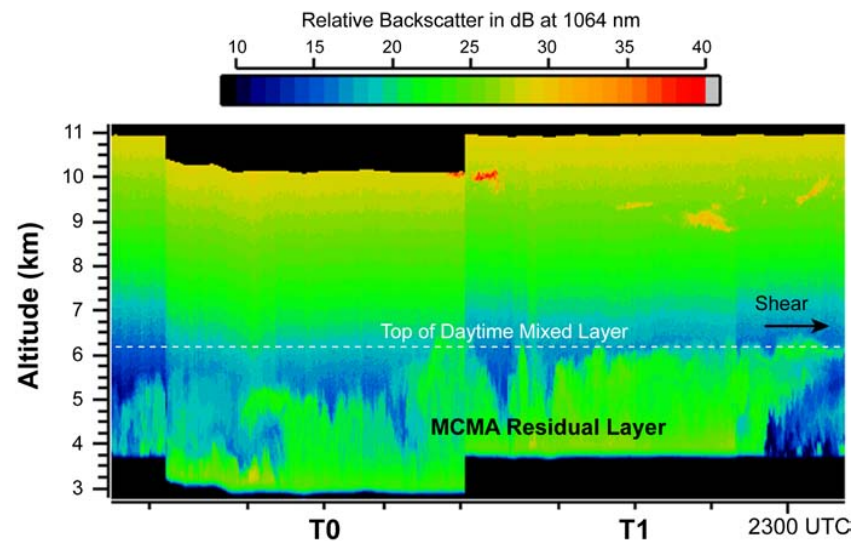

Fig. 8. Scanning Aerosol Backscatter LIDAR (SABL) infrared image from the $\mathrm{C}-130$ showing the polluted residual layer extending above $6000 \mathrm{~m}$ in Mexico City at approximately 23:00 UTC on 18 March. The eastward shear at $5-6 \mathrm{~km}$ is consistent with the westerly winds aloft that were measured at the same time by first CMET balloon sounding. Note that left and right both are to the east in this partially mirrored image because the $\mathrm{C}-130$ was flying northwest over T0 and the east over T1 (see Fig. 7b). The LIDAR was looking upwards and the C-130 was flying between 3-4 km m.s.l. Discontinuities, such as the step between T0 and T1, are due to turns and rapid changes in altitude compounded here by the approximate nature of this assembled image.

made by the balloons extended the vertical range of the measurements through a substantial layer between $2950-4400 \mathrm{~m}$ with less frequent soundings to as high as $4700 \mathrm{~m}$. The balloon observations show that the nighttime transport was dominated by complex flow and substantial heterogeneity in the meteorological fields.

Figure 9 shows a three-dimensional perspective of the balloon trajectories (colored by specific humidity) as they passed over the Sierra Madre Oriental and Coastal Plain. The balloon observations reveal sharp gradients in specific humidity with wet cool air at lower altitudes (reds and yellows), drier mixed urban air just above (greens), and even drier air from the free troposphere (blues) at the highest altitudes observed. This confluence of air masses was driven by directional wind shear with northwesterly flow below the balloons and southeasterly flow above. Superimposed on this pattern was more complex mixing influenced by terrain following, thermal stratification, and possibly nocturnal jets. Throughout the night, the two balloons measured large variations in humidity, wind speed, and wind direction, at times travelling nearly orthogonally to each other while at the same altitude and only a few kilometers apart. Averaged over time and space, however, this heterogeneity had little effect on the overall trajectories; the two balloons were within $10 \mathrm{~km}$ of each other as morning approached over the Coastal Plain $12 \mathrm{~h}$ after launch.

\subsection{Daytime transport over the Gulf of Mexico}

As the balloons passed over the Coastal Plain and the Gulf of Mexico, they were commanded to perform periodic deep soundings to characterize the flow regime. Figure 10 shows the resulting profiles interpolated to create two-dimensional fields of potential temperature, specific humidity, wind speed, and wind direction. The balloons were launched from Mexico City (at left in the four panels) and nearly reached US waters over the Gulf of Mexico (at right in the panels) after almost $30 \mathrm{~h}$ aloft.

The balloon trajectories, labelled CMET A and CMET $\mathrm{B}$ in Fig. 10a, contain within them the balloon measurements displayed as color spectra. The background color fields were created by averaging these data into 15 -mintime by $100-\mathrm{m}$-altitude bins and then interpolating (using inverse-distance-squared weighting) to fill in the empty bins. The interpolations were performed only for bins where balloon data existed within $0.3 \mathrm{~km}$-day distance units and these then used only balloon data within 0.6 distance units. The limits and the weighting function were empirically selected to match the approximate structure evident in the raw profiles; due to the high density of the measurements, the general appearance of the interpolation and the broad conclusions reached about transport are not sensitive to the exact interpolation parameters.

In Figure 10, the main nighttime portion of the transport is denoted by the dark shaded areas underlying the panels between 00:00 and 12:00 UTC. The aforementioned heterogeneity during this period is apparent in all of the meteorological fields (Fig. 10a-d). In the early morning hours, the partially mixed air mass separated from the Sierra Madre Oriental and flowed over the top of cooler and wetter air being advected from the northwest along the Coastal Plain. The cooler northwesterly jet is evident in the interpolated color fields and in the balloon profiles at approximately 12:00 and 18:00 UTC. The jet can be seen through its signature in potential temperature (light green in Fig. 10a), specific humidity (light blue in Fig. 10b), wind speed (red and yellow Fig. 10c), and wind direction (red in Fig. 10d).

The cooler air in this jet established a stable thermal structure that apparently separated the outflow from the terrain and sent it, at approximately constant altitude, out over the Gulf of Mexico. The lower portion of the outflow layer (2500-3500 m) appears to have been sheared to the east by the jet where it was intercepted by the $\mathrm{C}-130$ at midday on 19 March. At the nominal altitude of the balloons, the outflow experienced much less shear and was transported largely intact to the north where it was intercepted by the $\mathrm{C}-130$ in the late afternoon. These intercepts are discussed in Sects. 3.5 and 3.7.

A more precise understanding of transport and mixing can be gained directly from the profile measurements shown in Fig. 11a-d. The profiles were created by averaging the balloon sounding data by time period according to the color 


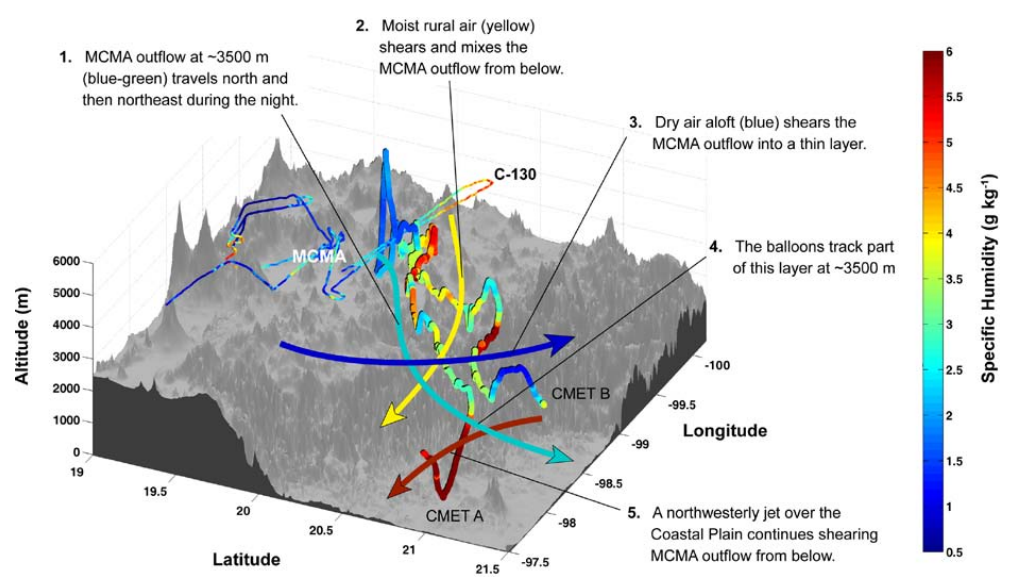

Fig. 9. CMET balloon trajectories on 18-19 March, colored by the observed specific humidity, leave Mexico City and extend jaggedy towards the viewer in the foreground. A portion of the 18-March C-130 flight, which occurred just before the balloon launch, is shown by the thin colored line in the background. The arrows, also colored by specific humidity, show the overall flow as inferred from the balloon soundings. The sheared layer of MCMA outflow forming here (blue-green arrow) is part of a much larger layer of MCMA outflow that spread over the Gulf of Mexico on 19 March and was intercepted several times by MILAGRO aircraft.

(a)

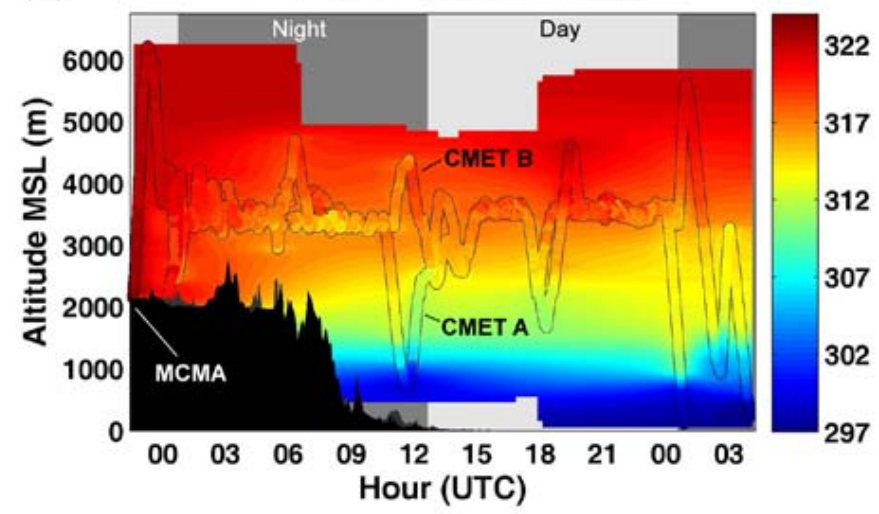

(c)

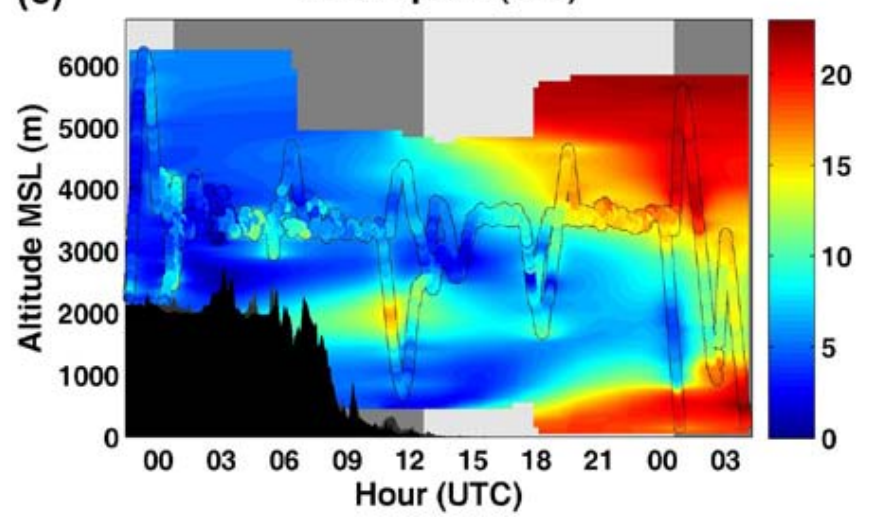

(b)

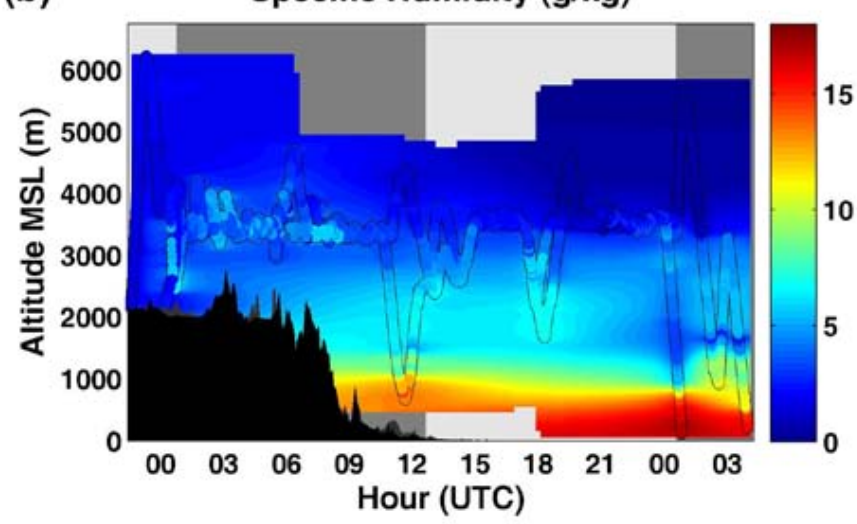

(d)

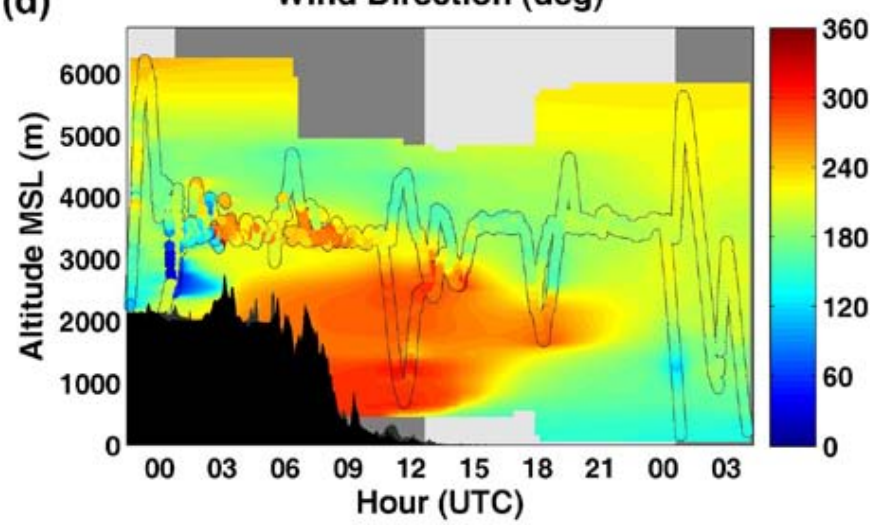

Fig. 10. Potential temperature (a), specific humidity (b), wind speed (c), and wind direction (d) interpolated from the CMET balloon measurements on 18-19 March. The balloon trajectories, labelled CMET A and CMET B in the upper left plot, contain within them the in-situ measurements as color spectra. The background color fields are inverse-square weighted interpolations of the balloon data (see text). Day and night are denoted by the underlying grey shading and the terrain is shown in black. 
(a)

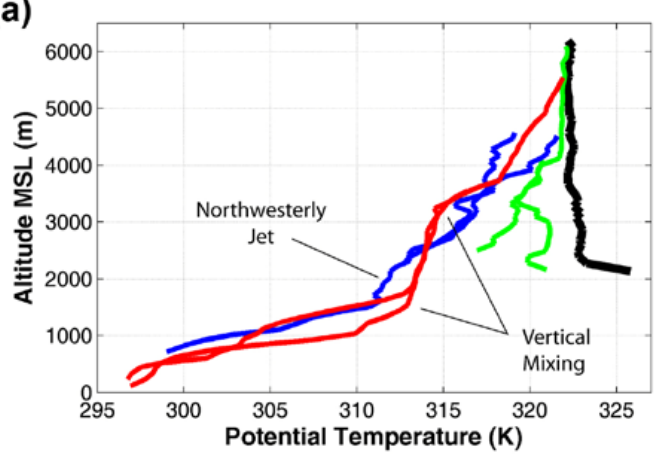

(c)

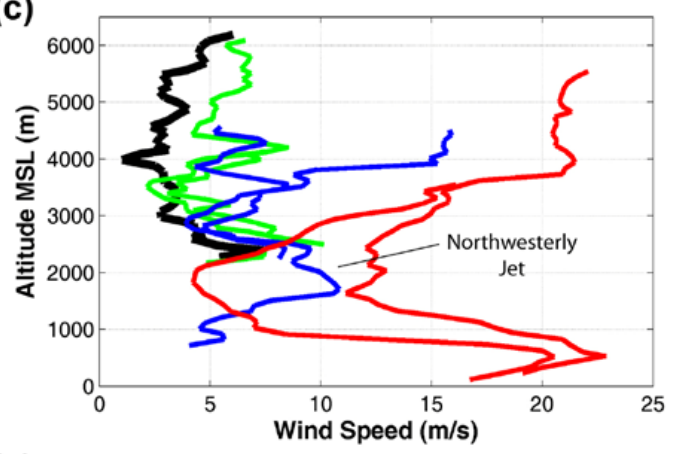

(b)

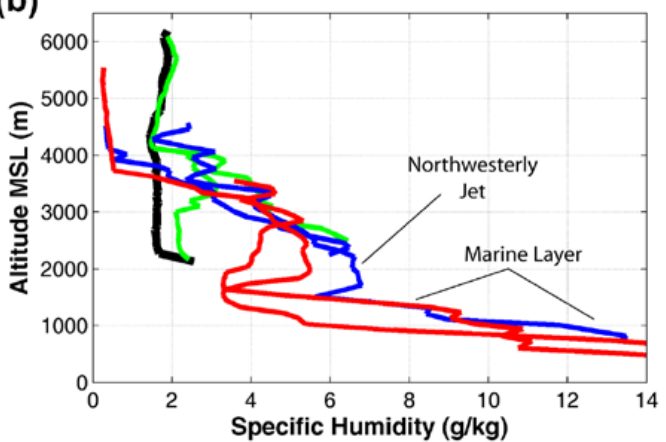

(d)

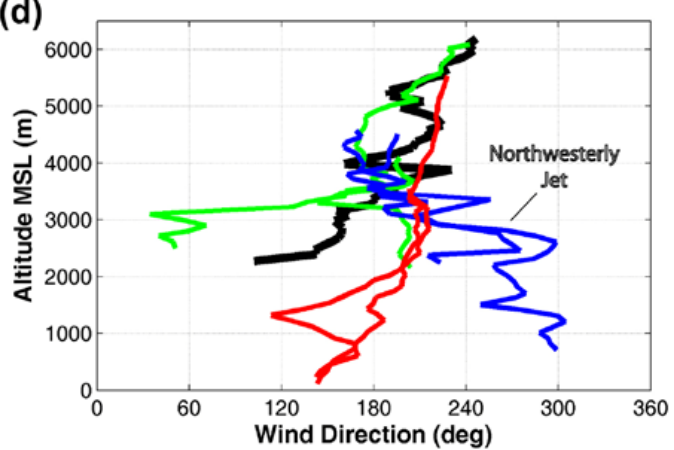

(e)

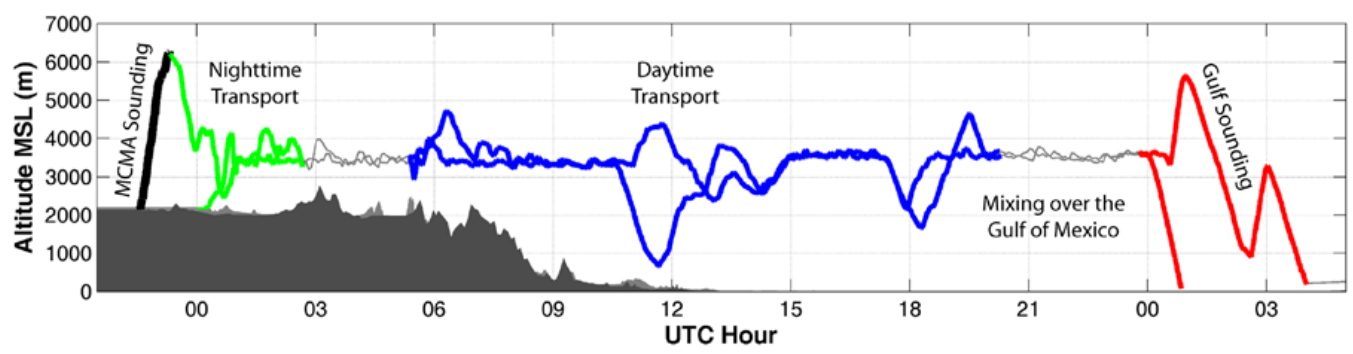

Fig. 11. Evolving profiles of potential temperature (a), specific humidity (b), wind speed (c), and wind direction (d) averaged for the four stages of transport (e) observed on 18-19 March: uniform MCMA air leaving the basin (black), nighttime transport over the Sierra Madre Oriental (green), daytime transport over the Coastal Plain and Gulf of Mexico (blue), and mixing over the Gulf of Mexico (red).

scheme in Fig. 11e. The average profiles for the CMET A and CMET B balloons are plotted separately for each time period (but not distinguished from each other) in order to show when variability is present in the meteorological fields.

The first sounding (black traces in Fig. 11a-d) occurred at launch near Mexico City and is from just one of the balloons (CMET A). The almost vertical profiles of potential temperature and specific humidity show that the air leaving the basin on 18 March was well mixed and that the top of the residual layer was above $6000 \mathrm{~m}$ (4000 m a.g.l.). Away from the surface, the winds were light $\left(2-5 \mathrm{~m} \mathrm{~s}^{-1}\right)$, relatively uniform, and from the south-southeast. Near the top of the residual layer, the winds increased to over $5 \mathrm{~m} \mathrm{~s}^{-1}$ and the direction turned towards the east. These winds would generally transport the pollution from the center of Mexico City towards the launch site (Fig. 7a) while shearing the top of the residual layer off towards the east as seen in the C-130 LIDAR imagery (Fig. 8).
A short distance downwind of MCMA, cool moist (and likely much cleaner) air began mixing into the outflow; the two balloons began reporting large differences in potential temperature, specific humidity, and wind direction, especially near the surface (diverging green traces in Fig. 11a, b ,d). Above $4000 \mathrm{~m}$, the balloons initially remained embedded in the undiluted outflow as evident from the consistent profiles there. During the next phase of the transport (blue traces in Fig. 11a-d), the balloons passed over the Gulf of Mexico at an approximately constant altitude of $3400 \mathrm{~m}$. The cool northwesterly jet that decoupled the outflow from the surface and sheared its lower reaches to the east is evident in all the profiles (Fig. 11a-d).

During the final portion of the flight over the Gulf of Mexico (red traces in Fig. 11a-d), the wind speed increased to more than $20 \mathrm{~m} \mathrm{~s}^{-1}$ both at the surface and aloft. At the same time, the temperature and humidity profiles reported by the two balloons, now $150 \mathrm{~km}$ apart, flatten dramatically 
(Fig. 11a-b). It is possible that the balloons, now travelling in the faster air at $3500 \mathrm{~m}$, passed over a different air mass and descended into it during the soundings. A more plausible explanation is that the flattening of the profiles represents a large-scale mixing event driven by warm-air advection near the surface, cool air advection aloft, or shear-induced turbulence. Non-condensing conditions $(\mathrm{RH}<60 \%)$ prevailed everywhere above the marine boundary layer and thus latent heat release was not likely a factor. The mixing scenario is consistent with the strong vertical wind shear that developed late in the day on 19 March (red lines Fig. 11c-d) and with the conservation of both potential temperature and specific humidity within the mixed layer (e.g., compare blue and red lines in Fig. 11a). The mixing nearly reached the altitude of the balloons and the associated outflow; if it had propagated a hundred meters higher, it likely would have dissipated the pollution encountered by the C-130 during one of the key intercepts of the 19 March flight.

The evolution of the MCMA outflow at higher altitudes is less certain because there are only a few CMET balloon soundings above $4500 \mathrm{~m}$. However, it is known that the residual layer was well mixed with a potential temperature of approximately $322 \mathrm{~K}$ and relative humidity less than $65 \%$ up to at least $6200 \mathrm{~m}$. Near the top of the residual layer, this potential temperature is similar to that of the surrounding free troposphere. At lower altitudes, the outflow is $1-5 \mathrm{~K}$ warmer than the surrounding air as evident from rawinsonde profiles (Mexico City and Acapulco stations) as well as from the CMET balloon soundings further downwind; the resulting buoyancy (3-15 $\mathrm{g} \mathrm{kg}^{-1}$ lift in balloon lexicon) likely makes the lower altitude outflow more susceptible to lofting and upward mixing into any cooler air advected overhead. The upper portions of the residual layer, which are similar in potential temperature to the free troposphere, may therefore be better preserved during long-range transport.

The most important information from the profile analysis, however, is that there appears to be no large-scale ascent or descent during the transport event. The profiles of potential temperature and specific humidity maintain their basic shapes and layer structure even as they evolve in time (see especially Fig. 11b). Such preservation of the structure would be unlikely if a significant portion of the outflow had followed the terrain down towards the Coastal Plain, for example. The more visual image of the transport (Fig. 10) reinforces this view that the MCMA outflow decoupled from the surface as it moved out over the Gulf of Mexico. Some vertical motion in the form of orographic waves, terrain following, and synoptic-scale convergence certainly does occur and is a significant uncertainty in the ensuing trajectory analysis. Overall, however, the effect of vertical motion appears to be small and a meaningful understanding of transport can be gained by assuming constant-altitude flow on 18-19 March. With this knowledge, the evolving wind profiles can be used to calculate trajectories in the general vicinity of the balloons over the entire altitude range of the soundings.

\subsection{Balloon-based trajectories}

In this section, horizontal trajectories are computed directly from the balloon wind profiles and used to advect the MCMA outflow over a period of approximately $30 \mathrm{~h}$. While such an approach may appear to be simplistic in comparison to more sophisticated transport models, it has the benefit of being tied irrefutably to observations. Thousands of independent wind measurements were made at approximately the right place and time for quantifying transport. Throughout this paper, balloon-based trajectories (or equivalently, computed trajectories) are those derived from the balloon wind measurements at each altitude level. These generally differ from the balloon trajectories themselves (i.e., the flight paths) because the balloons spend time at many different altitudes during flight.

\subsubsection{Trajectory calculations}

The balloon-based trajectories were computed using the interpolated wind fields shown in Fig. 10c-d and described in Sect. 3.4. These wind fields were generated by binning and averaging the balloon wind measurements and then interpolating over time and altitude to fill in the missing values. Once the fields were established, zonal and meridional winds could then be estimated at any time or altitude covered by the balloon flights and integrated forward in time to create trajectories. In the vertical dimension, the computed trajectories were constrained to constant-altitude surfaces, consistent with the findings from the profile analysis in the previous section. While more complex schemes are possible (e.g., terrain following or constant potential temperature), there is no evidence for widespread ascent or descent on 18-19 March; the constant-altitude trajectories are expected to be representative of the bulk transport.

The computed trajectories are most accurate when they remain close to the balloons (near to the wind measurements) and when the actual wind field is uniform at each altitude (i.e., a function of time but not space). The trajectories near the nominal float altitude of the balloons are therefore more exact than those far above or below which tend to diverge more rapidly from the balloon positions. The uniformity of the flow is evident in the wind profiles in Fig. 11; profiles from the two balloons (lines of the same color) almost invariably have the same magnitudes and vertical structure. The exceptions occur in the complex flow over the Sierra Madre Oriental (green lines diverge) and at the end of the flight when the flow is accelerating and the profiles are measured at different times (red lines). The many small differences in the wind profiles average out during the integration of the trajectories and therefore have little effect on the overall results. In the end, the trajectories at each altitude are computed individually using independent wind observations at each altitude level; their subsequent stacking to form coherent structures 

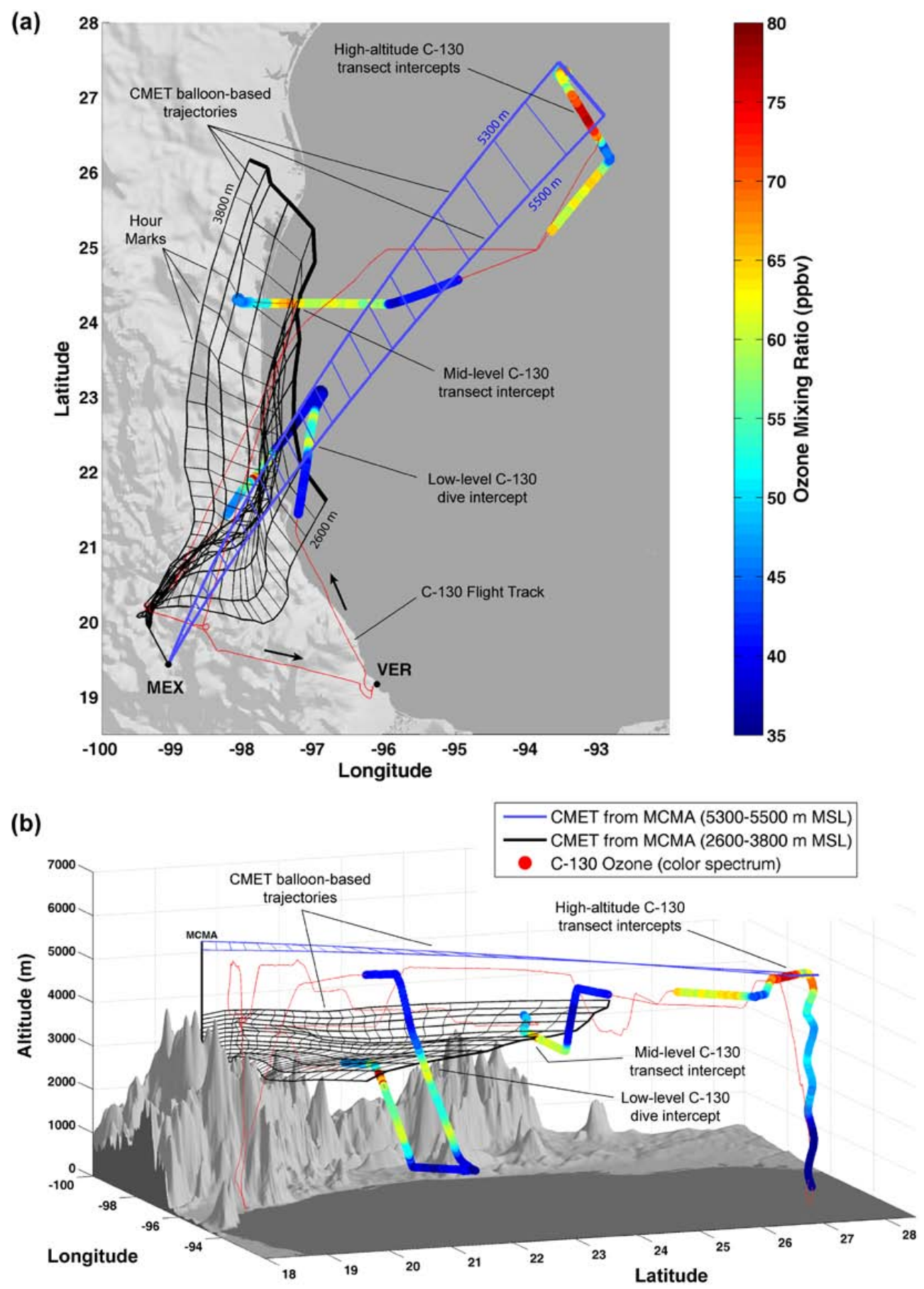

Fig. 12. Overview map (a) and three-dimensional plot (b) of the balloon-based trajectories originating from MCMA in the late afternoon of $18 \mathrm{March}$ and continuing for $25 \mathrm{~h}$ to the northeast. The trajectories were calculated directly from the CMET balloon winds and run at constant altitudes (100-m or 200-m intervals) with 1-h time intervals forming the mesh. The C-130 flight track on 19 March (thin red line) is highlighted by the observed $\mathrm{O}_{3}$ mixing ratio (in color) where it approaches the outflow trajectories. From top to bottom in the figures, the intercepts are identified as the high-altitude transects, the mid-level transect, and the low-level dive. A fifth probable intercept (the low-level climb) can be seen under the black mesh to the left of the dive intercept. Ozone is used as an approximate urban tracer here because the CO instrument was briefly offline during one of the intercepts. The tracer observations made by the C-130 during the intercepts are described in detail in Sect. 3.7. 
Table 2. Summary of long-range MCMA transport pathways intercepted by the C-130 on 19 March. For each intercept, the table gives the time range (rounded to the nearest minute), the median latitude, longitude, altitude, distance from the center of MCMA, and the approximate plume age based on the computed trajectories. The phase mismatch column specifies the number of hours by which the C-130 led (positive) or lagged (negative) the trajectories in arriving at the intercept location. Intercepts with the lowest phase mismatch and largest number of wind measurements have the greatest certainty (far right column).

\begin{tabular}{|c|c|c|c|c|c|c|c|}
\hline Intercept & $\begin{array}{l}\text { UTC Time } \\
\text { (start/end) }\end{array}$ & $\begin{array}{l}\text { Location } \\
\text { (lat/long) }\end{array}$ & $\begin{array}{l}\text { Altitude } \\
\text { (m) }\end{array}$ & $\begin{array}{c}\text { Distance } \\
(\mathrm{km})\end{array}$ & $\begin{array}{l}\text { Age } \\
\text { (h) }\end{array}$ & $\begin{array}{l}\text { Phase } \\
\text { (h) }\end{array}$ & Certainty \\
\hline $\begin{array}{l}\text { Low-level } \\
\text { (dive) }\end{array}$ & $\begin{array}{l}18: 18 \\
18: 22\end{array}$ & $\begin{array}{l}22.37^{\circ} \mathrm{N} \\
97.10^{\circ} \mathrm{W}\end{array}$ & 2670 & 380 & $\sim 26$ & +6 & Low \\
\hline $\begin{array}{l}\text { Low-level } \\
\text { (climb) }\end{array}$ & $\begin{array}{l}18: 53 \\
18: 58\end{array}$ & $\begin{array}{l}21.86^{\circ} \mathrm{N} \\
97.94^{\circ} \mathrm{W}\end{array}$ & 2610 & 290 & $\sim 16$ & -4 & Low \\
\hline $\begin{array}{l}\text { High-altitude } \\
\text { (transect } 1)\end{array}$ & $\begin{array}{l}21: 18 \\
21: 36\end{array}$ & $\begin{array}{l}26.95^{\circ} \mathrm{N} \\
93.33^{\circ} \mathrm{W}\end{array}$ & 5390 & 1020 & $\sim 24$ & +1 & Med \\
\hline $\begin{array}{l}\text { High-altitude } \\
\text { (transect 2) }\end{array}$ & $\begin{array}{l}22: 05 \\
22: 18\end{array}$ & $\begin{array}{l}26.50^{\circ} \mathrm{N} \\
93.12^{\circ} \mathrm{W}\end{array}$ & 5360 & 1000 & $\sim 24$ & +0 & Med \\
\hline $\begin{array}{l}\text { Mid-level } \\
\text { (transect) }\end{array}$ & $\begin{array}{l}23: 25 \\
23: 33\end{array}$ & $\begin{array}{l}24.25^{\circ} \mathrm{N} \\
97.40^{\circ} \mathrm{W}\end{array}$ & 3240 & 560 & $\sim 24$ & -1 & High \\
\hline
\end{tabular}

attests to the validity of the technique and the high accuracy of the GPS wind data.

\subsubsection{Trajectory intercepts with the C-130}

The computed trajectories for the 18-19 March transport event are shown in Fig. 12. The lower-altitude trajectories (black) were initialized from the Tepeji del Río launch site at 00:00 UTC on 18 March and then advected along with the balloons. High-altitude trajectories (blue) were started in the center of the city one hour earlier when the polluted residual layer was known to be at that location. The trajectories are shown as the thicker horizontally oriented lines at 100-m (black) or 200-m (blue) altitude intervals; one-hour time interval lines create the mesh. The lower set of 11 trajectories are the most accurate as they are derived from 2412 individual wind measurements in the $2600-3600 \mathrm{~m}$ range. The high-altitude trajectories are based on two soundings made $25.7 \mathrm{~h}$ apart and are therefore addressed separately in the discussion. Trajectories between these levels have been left off the plot to preserve its visual clarity.

When the balloon-based trajectories are run forward from Mexico City, they intercept the C-130 flight track on three occasions at approximately the correct latitude, longitude, altitude, and time. These intercepts include a dive and subsequent climb near $22^{\circ} \mathrm{N}$ latitude (18:18-18:22 UTC and 18:53-18:58 UTC respectively), a pair of high-altitude transects near $26.5^{\circ} \mathrm{N}(21: 18-21: 36$ UTC and 22:05-22:18 UTC respectively), and a mid-level transect that deliberately crossed the paths of the two CMET balloons near $24^{\circ} \mathrm{N}$ lati- tude (23:25-23:33 UTC). Table 2 and its header provide additional information about the intercepts. During all three intercepts (five if the paired events are counted separately), the urban tracer species measured by the C-130 peak at the times and locations expected from the balloon-based trajectories. In Fig. 12, ozone is used as an urban tracer species because it is measured at high time resolution (1-s) and the data are available during all three intercepts; to maintain the clarity of the image, the C-130 flight track (red line) is colored by the measured ozone mixing ratio only in the vicinity of the intercepts.

The intentional mid-level transect is the most certain of three because it is well aligned with the balloon-based trajectories in both space and time and because the CMET balloons were in close proximity to the outflow at this altitude. The trajectories initialized at the balloon launch site (Tepeji del Río at 22:30 UTC) arrive at the intercept location after approximately $24 \mathrm{~h}, 1 \mathrm{~h}$ before the $\mathrm{C}-130$. Trajectories from the center of MCMA, while less exact in their timing, arrive after approximately $25.5 \mathrm{~h}(0.5 \mathrm{~h}$ after the aircraft has passed). As discussed in Sect. 3.7, the computed trajectories and the CMET B balloon both cross the C-130 transect near the point where the mixing ratios of urban tracers peak. The CMET B balloon is considered to be the more reliable marker of the mid-level outflow because it performed fewer and shallower soundings; the CMET A balloon descended deep into the northwesterly jet and, in doing so, was transposed more than $100 \mathrm{~km}$ to the east. 


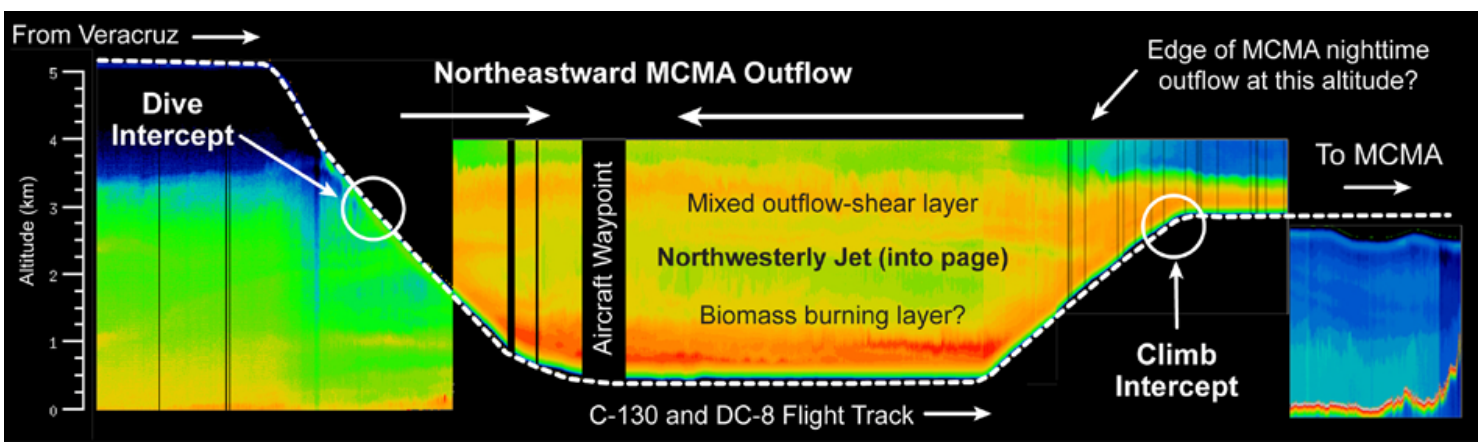

Fig. 13. SABL image from the C-130 dive under probable MCMA outflow near the Veracruz coastline on 19 March. The balloon-based trajectories place the MCMA outflow above the C-130 when it is at the bottom of the dive. The polluted layers that were intercepted during the dive and climb (shown by the two circles) appear to be outflow that left MCMA on 18 March and was sheared to the southeast by a mesoscale jet. Note that the SABL image is in two planes: on the left, the C-130 is heading north while on the right (after the aircraft waypoint), it is heading south-southwest towards Mexico City.

In comparison with the mid-level intercept, the $\mathrm{C}$-130 dive and climb intercepts were not as well matched in time or as close to the CMET balloons. The dive occurred more than $6 \mathrm{~h}$ before the 26-h trajectories from Tepeji del Río arrived at the intercept location. The subsequent climb occurred approximately $4 \mathrm{~h}$ after the $16-\mathrm{h}$ trajectories had passed. This uncertainty in timing is compounded by the fact that there were few CMET balloon soundings in the complex flow below $3000 \mathrm{~m}$ during the night and by the strong northwesterly shear that likely mixed into the outflow as it passed over the Coastal Plain the next morning. The dive and climb intercepts should therefore be interpreted conservatively; both, however, are at approximately the correct location and time to have sampled low-level MCMA outflow from the previous day and night. Figure 13 shows the SABL (LIDAR) imagery from the C-130 as it flew in tandem with the NASA DC-8 directly underneath the probable location of the outflow. The C-130 dive and climb intercepts bracket this underpass.

The high-altitude trajectories, which track the top of the MCMA residual layer, are also subject to significant uncertainty. These trajectories are at the upper limit of the CMET balloon altitude range and are therefore based largely on the two deep soundings shown in Fig. 11e. The first sounding was made in MCMA (18 March at 23:30 UTC) and the second was performed over the Gulf of Mexico $25 \mathrm{~h}$ later (20 March at 00:30 UTC). During this time interval, the wind direction was remarkably steady over the relevant altitude range of 5000-5600 m (Fig. 11d). The wind speed, while increasing with time, was nearly invariant over the range 4000$5600 \mathrm{~m}$ (black, red, and right blue lines in Fig. 11c). These attributes of the upper-level winds on 18-19 March allow trajectories to be calculated directly from the two soundings. The simplest calculation advects the MCMA residual layer using wind speed and direction estimated by linear interpolation between the sounding times. The resulting trajectories directly intercept the most heavily polluted air observed by the C-130 over the Gulf of Mexico on 19 March. The trajectories, however, are too fast and arrive at the C-130 intercept location $1-2 \mathrm{~h}$ before the aircraft.

These linearly interpolated trajectories represent an upper bound with respect to length because the actual wind speed increases only near the end of the flight, at least over the range $4000-4500 \mathrm{~m}$ where sufficient data are available to determine the time dependence (Fig. 11c). A more nuanced trajectory calculation takes the observed acceleration into account by using the measured wind speed from a third sounding (up to $4640 \mathrm{~m}$ at 18:20 UTC) as a lower-bound estimate of the wind speed at $5000 \mathrm{~m}$ at this time. The winds for the trajectory calculation are then parameterized using a quadratic fit (to the three wind profiles) rather than the linear interpolation used previously. These lower-bound trajectories also cross the C-130 flight track at the location of highest pollution but are slightly too short, intercepting the C-130 location $2-3 \mathrm{~h}$ after the aircraft has past. Trajectories between these upper and lower bounds, originating over the center of MCMA at 22:30 UTC on 18 March, plausibly intercept the C-130 over the Gulf of Mexico during its two highaltitude transects (21:18-22:18 UTC on 19 March). Since the mixed layer over MCMA only exceeded $5000 \mathrm{~m}$ altitude late in the afternoon on 19 March (after 21:00 UTC based on the T1 LIDAR) the intercepted outflow would likely have begun its journey at around the start time of the trajectories (22:30 UTC) and would therefore be approximately $24 \mathrm{~h}$ old at the time of the intercept.

It is also noteworthy that the vertical wind shear in the computed trajectories is nearly identical to that observed by the $\mathrm{C}-130$ in the urban tracer signature. Figure 14 shows an elevation view looking southwest from the Gulf of Mexico towards MCMA with the trajectories and C-130 ozone measurements in the foreground. The high-altitude trajectories originating from the center of MCMA are light blue with their 24-h ending location in bold. 


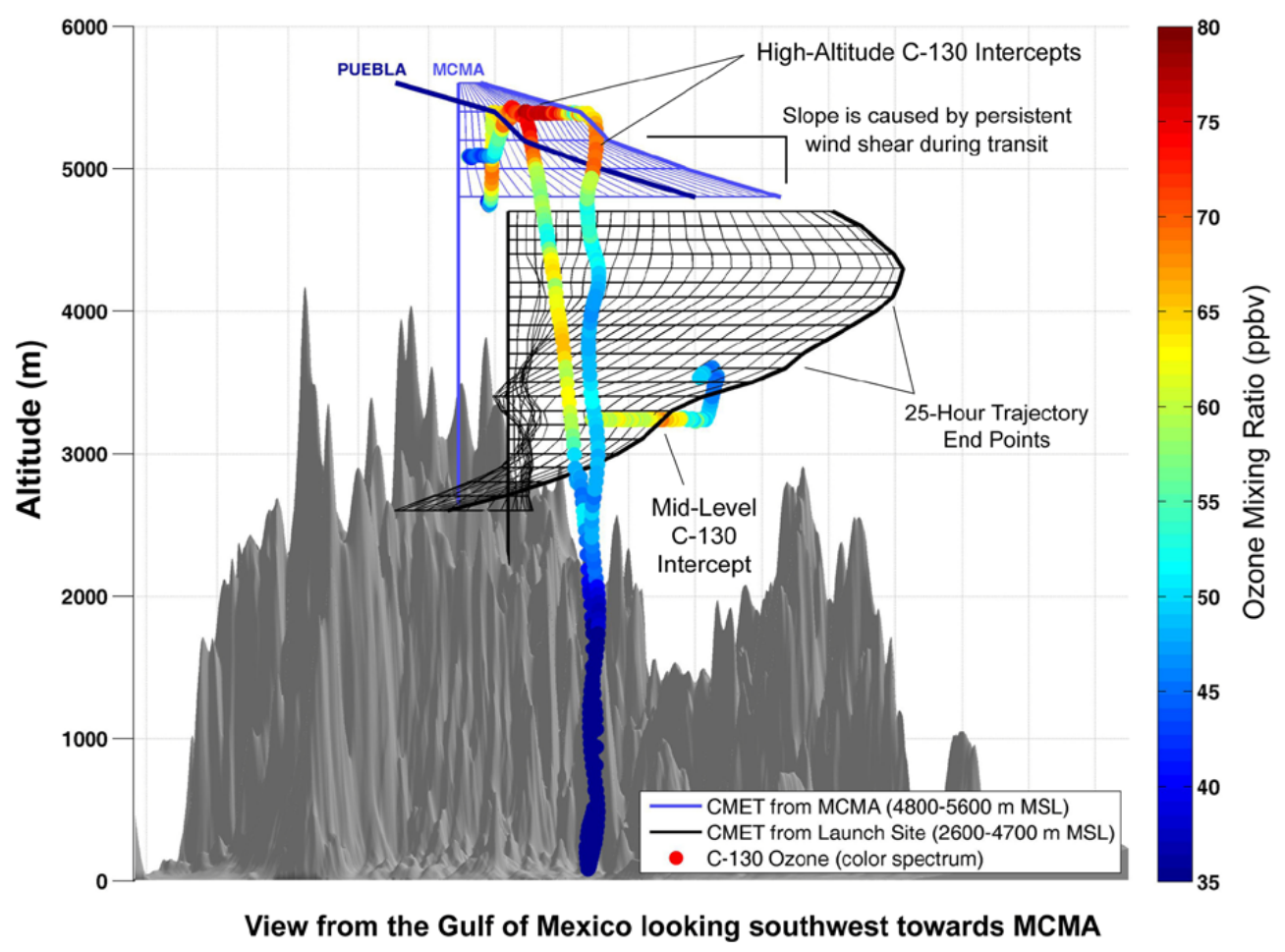

Fig. 14. Elevation view of the balloon-based trajectories and C-130 ozone measurements (in color) for the 18-19 March MCMA outflow event. The constant-altitude trajectories (horizontal blue lines above and black below) extend from MCMA in the background towards the viewer. The mesh is created by the 1-h time-interval lines, the last of which is the locus of 25 -h end points shown as bold lines on the right. The diagonal structure in the high-altitude ozone field (red band) closely matches the slope of the blue end-position line, an indication that the balloon-based trajectories accurately describe the actual transport. Trajectories from Puebla, while much less certain than those from MCMA, are shown as their end position only (in dark blue) to give a sense of the uncertainty in source attribution.

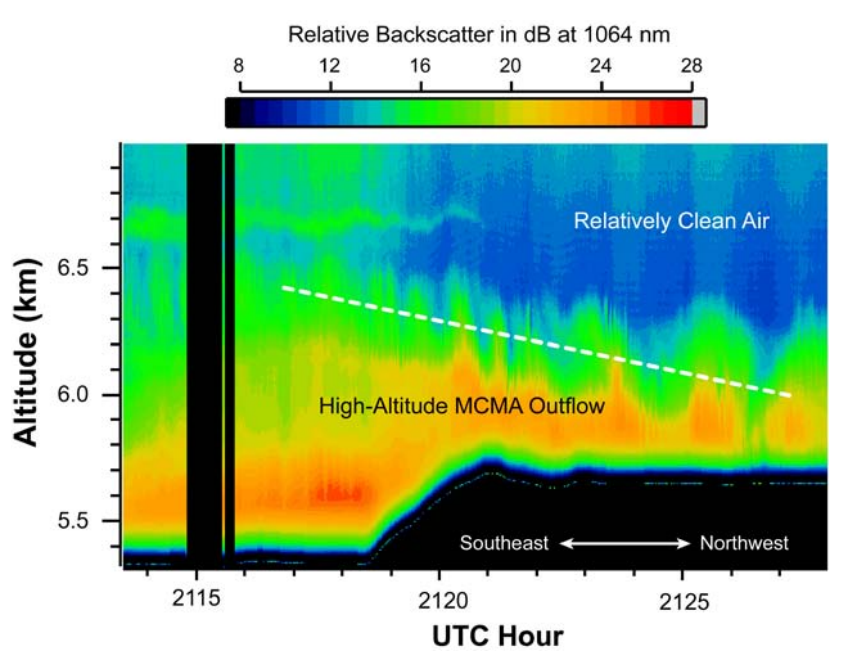

Fig. 15. SABL image of what may be the upper portion of the MCMA residual mixed layer approximately one day after it left Mexico City. The slope (white dashed line) approximately matches the shear seen in the balloon-based trajectories. Urban tracer concentrations (notably MTBE) peak along the entire high-altitude portion of the flight track (after 21:20 UTC).
The shear in the computed trajectories (manifested as a slope in the MCMA endpoint line) matches almost exactly the diagonal structure in both the ozone field (red and yellow bands sloping downward to the right) and in the SABL imagery (Fig. 15). The agreement between the observed and calculated shear indicates that the transit time and cumulative wind shear estimated from the balloons is likely very similar to that of the actual atmosphere.

Given the uncertainty in the high-altitude trajectories, however, it is not possible to attribute the intercept definitively to MCMA. Balloon-based trajectories originating from the Puebla/Atlixco area (pop. 1.6 million), while even less certain due to their distance from the balloons, also intercept the apparent outflow (dark blue Puebla endpoint line in Fig. 14). Even so, the large size of the polluted air mass and its good alignment with the MCMA trajectories are consistent with an MCMA intercept. Furthermore, if the pollution encountered by the $\mathrm{C}-130$ was from Puebla/Atlixco, then the MCMA layer would likely be visible above where there is only clear air in the C-130 SABL imagery (Fig. 15).

The balloon-based trajectories can also be used to identify C-130 measurements that are unlikely to have originated from MCMA. For example, the northward flow evident at 


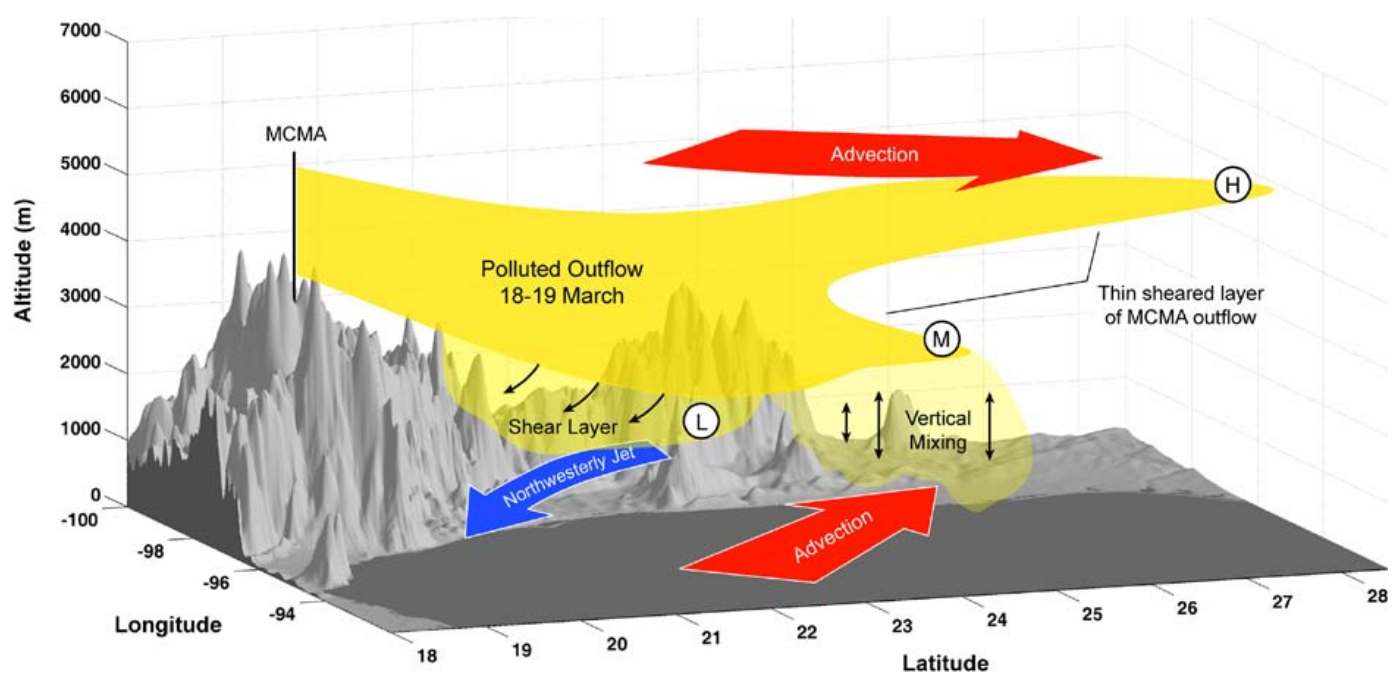

Fig. 16. Cartoon summarizing the main features of the long-range transport of MCMA pollution on 18-19 March. These include the northwesterly jet that sheared the lower portions of the outflow to the east, the advection that likely caused the extensive mixing of the lower portion of the outflow over the Gulf of Mexico, and shear-induced layer formation at higher altitudes. The three long-range C-130 intercepts are designated by the circle symbols ( $\mathrm{L}=$ low-level intercept, $\mathrm{M}=$ mid-level intercept, and $\mathrm{H}=$ high-altitude intercept).

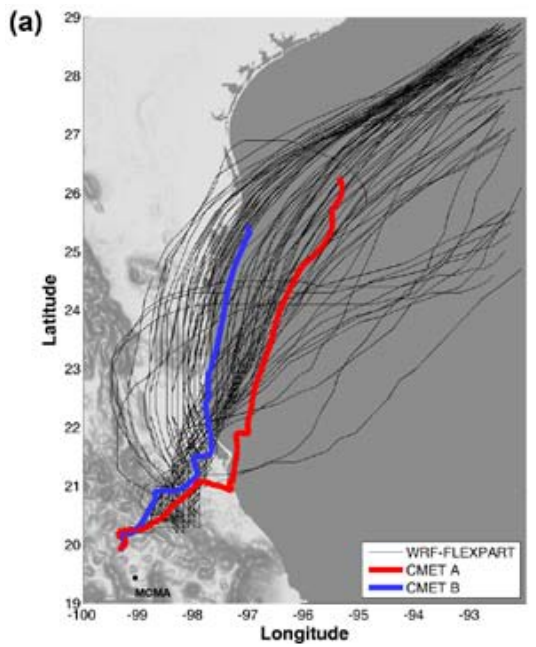

\section{(b)}

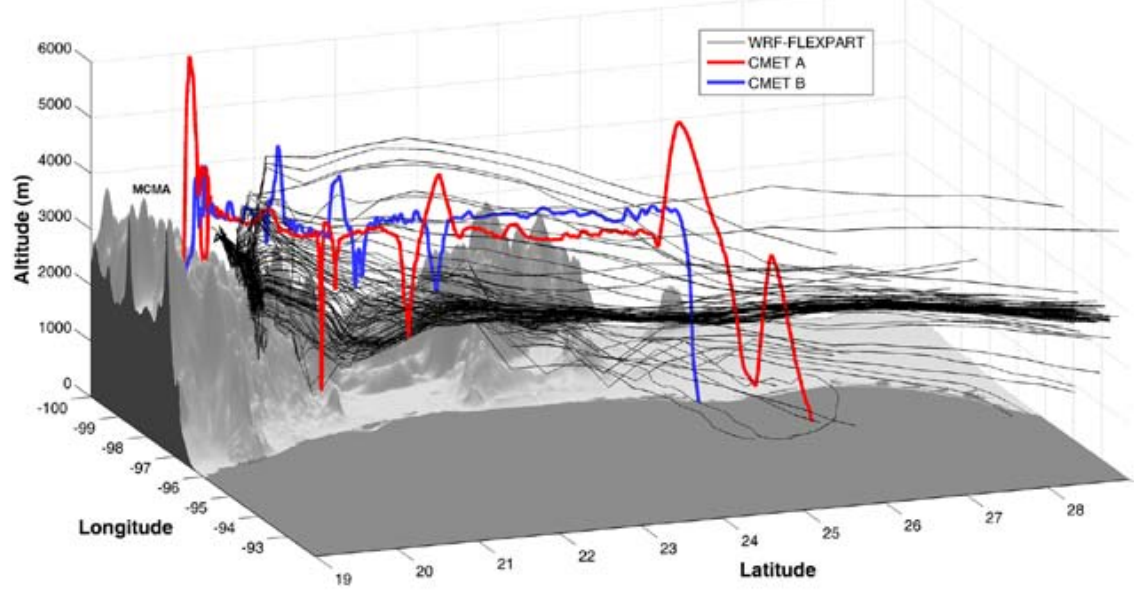

Fig. 17. (a) WRF-FLEXPART trajectories (black) for particles released at $3400 \mathrm{~m}$ altitude at the time and location of the first CMET balloon launch and advected forward for $24 \mathrm{~h}$. The balloon flight tracks are shown in red and blue. (b) Three-dimensional view of the same model run shows how the trajectories follow the terrain down over the Coastal Plain. The balloon profiles in Figs. 10 and 11 imply that the outflow decoupled from the surface.

mid levels in Fig. $14(3500-5000 \mathrm{~m})$ and in Fig. 12 (near $3800 \mathrm{~m}$ ) suggest that any pollution encountered by the C130 at these levels over the Gulf of Mexico likely originated far to the east of MCMA. Some probable urban intercepts during the C-130 flight over the Gulf of Mexico (e.g., 410 ppt MTBE, 20:40-20:58 UTC) may have originated from the Puebla plateau.

Figure 16 summarizes the main features of the 1819 March MCMA outflow event and shows the relative locations of the three C-130 aircraft intercepts on 19 March.

\subsection{WRF-FLEXPART model trajectories}

The transport models used in the MILAGRO campaign predict the same overall northward transport that was observed by the CMET balloons on 18-19 March. The models, however, differ considerably from the balloon observations in some of the details. Figure 17, for example, shows WRFFLEXPART model predictions (here based on WRF using the GFS analysis step) for an ensemble of particles released at $3400 \mathrm{~m}$ altitude at the time and location of the CMET balloon launch. Viewed from above (Fig. 17a), the model 
trajectories overlay the balloon tracks with high fidelity. Furthermore, the model captures some of the mixing and dispersion that is occurring in the atmosphere but is not measured by the balloons or captured in the simple trajectories in Fig. 12. As shown in Fig. 17b, however, the WRFFLEXPART trajectories do not decouple from the surface over the Sierra Madre Oriental, but rather follow the downward slope and decouple at much lower altitude over the Coastal Plain as described by Fast et al. (2007). This difference in terrain-following behavior is likely due to the cool northwesterly jet that is seen in the balloon profiles (e.g., Fig. 10) but appears to be absent in the models. These two scenarios describe the same general transport to the northeast, but have different implications for the dispersion of the MCMA pollutants and potential impact on surface-level air quality downwind. It remains to be determined how the MCMA outflow typically behaves and if the event of 18 19 March was representative of northeastward transport more generally. It is apparent, however, that mesoscale thermal structure can have substantial effects on the MCMA outflow by modulating both vertical mixing and terrain following behavior. Like the orographic density circulations that drive local transport within the MCMA basin (Doran and Zhong, 2000; deFoy et al., 2005), the thermal structure and winds of the larger Mesa Alta may have significant effects on regional transport.

\subsection{Aircraft tracer observations during trajectory intercepts}

The three aircraft intercepts with balloon-based trajectories are examined more closely here using a small subset of the chemical and tracer measurements on the C-130. The goal of the analysis was to determine if the trajectory intercepts are aligned with features in the tracer field that are consistent with MCMA air. Such alignment would generally increase confidence in the balloon-based trajectories and the transport scenarios described in this paper. The first of the trajectory intercepts, a C-130 dive early in the flight, likely sampled the layer of sheared outflow being transported over the Coastal Plain. The second intercept was the highest in altitude and furthest downwind; it is linked by the trajectories to the top of the MCMA residual layer from the previous day. The final intercept, the transect deliberately made by the C-130 across the path of the balloons, also occurred over the Gulf of Mexico but at much lower altitude $(3240 \mathrm{~m})$ and approximately $400 \mathrm{~km}$ closer to Mexico City.

During the initial dive intercept, the $\mathrm{C}-130$ passed through a substantial layer of pollution (2500-3200 m) near the top of the northwesterly jet. The balloon-based trajectories suggest that this air likely left MCMA approximately $26 \mathrm{~h}$ prior to sampling, most probably during the afternoon. The C-130 profile (Fig. 18a) shows marked increases in both MTBE (an urban tracer) and HCN (and indicator of biomass burning) in what appears to be the MCMA layer. Below this, rela- tively clean air separates the MCMA outflow from another polluted layer at $1500 \mathrm{~m}$ (also visible Fig. 12b below the C130 dive intercept). This lower layer may be biomass burning pollution or, perhaps less likely, a branch of the MCMA outflow that followed the descending terrain and spread out over the marine boundary layer as simulated by the FLEXPART model (Fig 17b).

Because the MTBE measurements were reported at lower temporal resolution, the fine-scale structure of the layers is shown by $\mathrm{O}_{3}$ and $\mathrm{NO}_{\mathrm{y}}$, used here as proxies for $\mathrm{CO}$ which was momentarily offline. As the sum of all oxidized nitrogen-containing species, $\mathrm{NO}_{\mathrm{y}}$ tends to be conserved during transport and therefore acts as an approximate tracer of combustion. Ozone is not considered to be a reliable tracer due to the significant production and loss that can occur on a time scale of hours; it is, however, an indicator of anthropogentic influence, a criteria pollutant, and a reactive trace gas that has substantial influence on the overall chemistry. The heavy biomass burning in and around the MCMA basin (Yokelson, 2007; Crounse et al., 2009) typically confounds the urban and rural signatures, especially during the dry season in March. The elevated concentrations of both $\mathrm{HCN}$ and MTBE measured in the upper portion of the dive intercept (Fig. 18a) are therefore consistent with the conflated signature of MCMA air. The much lower concentration of MTBE (relative to $\mathrm{HCN}$ ) in the lower layer suggests it may be of rural origin.

The high-altitude intercept, which occurs at approximately $5400 \mathrm{~m}$, is linked by the balloon-based trajectories to the top of the MCMA residual layer. Figure $18 \mathrm{~b}$ shows that while this intercept was similar to the others for $\mathrm{CO}, \mathrm{O}_{3}$, and $\mathrm{HCN}$ (see caption), the mixing ratio of MTBE ( $\sim 40 \mathrm{pptv})$ was more than double that of the other intercepts. The highly elevated MTBE may be the result of a more direct intercept with the MCMA air, the inherent stability of the upper mixed layer, reduced turbulent mixing aloft, pollutant concentration in the daytime inversion (e.g., Lu and Turko, 1999; Raga and Raga, 2000), or some combination of these factors.

The tracer plot for the final (mid-level) intercept is shown in Fig. 18c. The balloon-based trajectories originating from MCMA extend through the plot (coming towards the viewer) at approximately the same location as the actual CMET B balloon (blue circle). From the trajectories, this intercept appears to be outflow that was transported several hundred meters above the northwesterly jet. The alignment of the peak tracer concentrations with the MCMA trajectories is notable, especially for the distinctly urban tracer MTBE. The trajectories are approximately an hour downwind of the C$130(\sim 50 \mathrm{~km})$ at the time of the intercept, implying that the tracer peak in Fig. 18c may correspond to a trailing portion of the MCMA residual layer. 

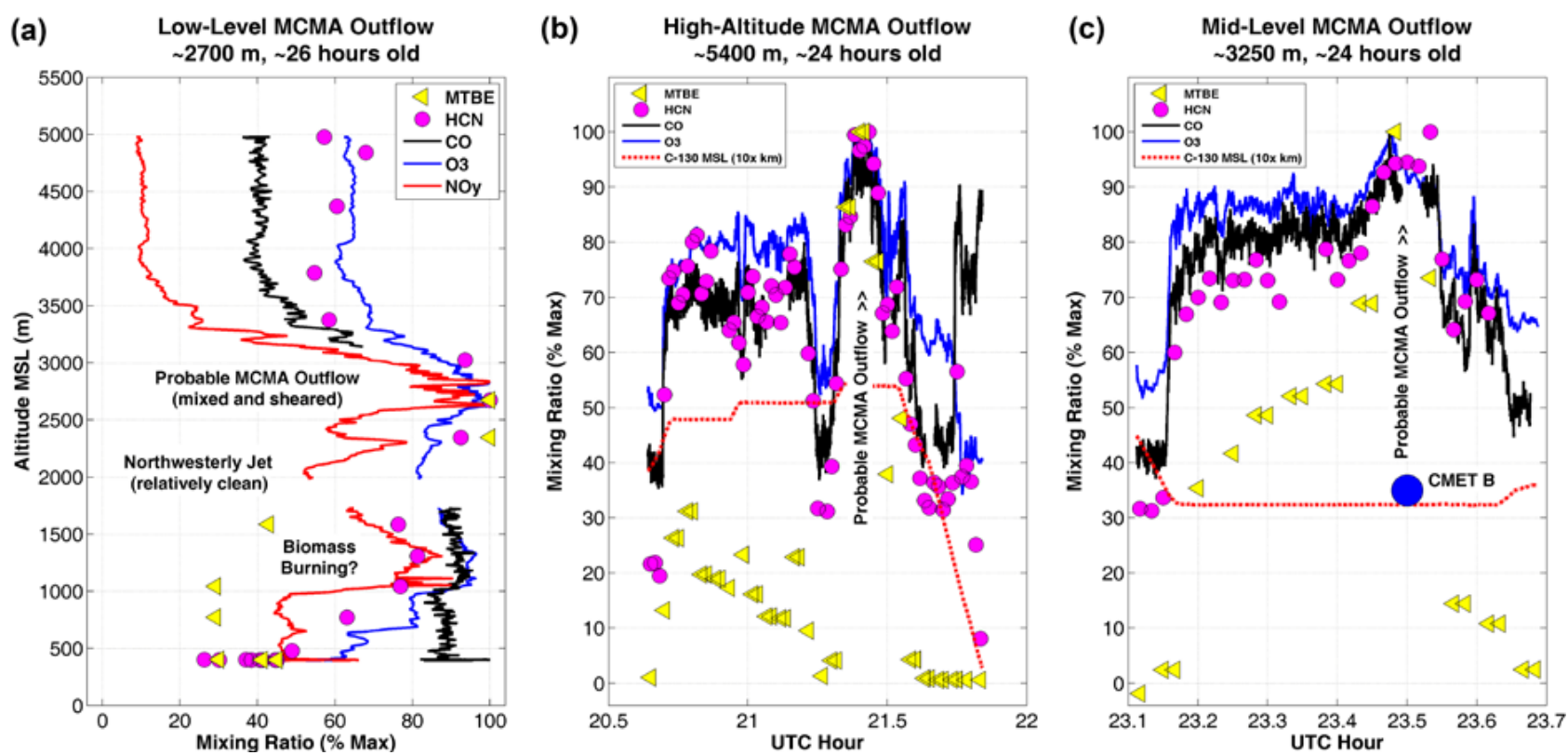

Fig. 18. One-day-old MCMA outflow as measured by the C-130 during the three intercepts with the balloon-based trajectories on 19 March. Biomass and urban tracers ( $\mathrm{HCN}$ and MTBE respectively) define the plume while $\mathrm{O}_{3}, \mathrm{NO}_{\mathrm{y}}$, and $\mathrm{CO}$ provide higher spatial resolution. (a) The C-130 dive likely intercepted a mixed and sheared layer of MCMA pollution from the previous afternoon. (b) The high-altitude transect is linked to the top of the MCMA residual layer from the previous evening. (c) During the one deliberate C-130 intercept with a CMET balloon (mid-level transect intercept), urban tracer concentrations peaked almost exactly at the balloon location (blue circle). All three trajectory intercepts are characterized by elevated ratios of MTBE/HCN. The mixing ratios in the three panels are plotted as percentages of the maximum value in the interval for each species. The respective maxima for panels (a), (b), (c) are: $\mathrm{O}_{3}(64,78,70 \mathrm{ppbv}), \mathrm{CO}$ (160, 161, $151 \mathrm{ppbv}), \mathrm{HCN}(447,529,533 \mathrm{pptv}), \operatorname{MTBE}(14.0,29.5,10.5 \mathrm{pptv}), \mathrm{NO}_{\mathrm{y}}$ (2261 pptv in panel (a) only). The intercept times for the three panels are: 18:18-18:23 UTC, 21:19-21:36 UTC, and 23:25-23:33 UTC on 19 March.

While it is possible that the urban tracers measured during the mid-level intercept had a source other than MCMA, such a coincidence appears unlikely. The winds along the trajectory at that altitude $(3240 \pm 50 \mathrm{~m})$ are well known from 30 shallow CMET balloon soundings comprising 150 independent measurements uniformly distributed in time and space. Furthermore, the extensive vertical mixing, seen in the potential temperature profiles, was mostly confined to lower altitudes. The elevated background pollution to the east (left of the intercept in Fig. 18c) may also be associated with MCMA and its surroundings, consistent with the CMET B balloon marking the western portion of the outflow and with the eastward shear and vertical mixing known to be occurring below.

All three C-130 intercepts are notable in that the urban tracer concentrations peak where the trajectories predict they should and not at other locations nearby. In every case, the ratio of MTBE to $\mathrm{HCN}$ falls by approximately half outside of the trajectory intercept. Additional improbable matches are found in the wind shear (Fig. 14), the SABL imagery (Figs. 13, 15), and in the absence of unexplained urban features along the C-130 flight track. Furthermore, during the analysis, many variations of the trajectory calculations were tested with different fitting schemes, initializations, and assumptions. Invariably, all of these tests arrived at approximately the same result showing the three intercepts de- scribed in this paper. This consistency may be attributable to the large number of in-situ wind measurements constraining the trajectories, the uniformity of the wind fields on 18 19 March, and the substantial size of the MCMA outflow, which dwarfs the many smaller anomalies in the meteorological fields. Collectively, these factors suggest that the transport of MCMA pollution on 18-19 March is well understood.

\section{Summary and conclusions}

A major goal of the MILAGRO campaign was to determine the regional impacts of air pollution outflow from Mexico City, one of the largest megacities in the western hemisphere. This paper analyzes the transport during one of the most significant outflow events of the campaign, that of 18 19 March 2006. The outflow was sampled multiple times by three MILAGRO aircraft and tracked over a wide range of altitude by two of our controllable CMET balloons. Over 29-h period, the balloons performed 20 soundings and made 4850 observations of winds and state variables as they drifted from MCMA out over the Gulf of Mexico.

Trajectories computed directly from the balloon winds identify three transport pathways on 18-19 March: lowlevel outflow that was sheared above the Coastal Plain by 
a mesoscale jet, mid-level outflow that travelled north along coastline with little shear, and high-altitude outflow that carried the upper portion of the MCMA residual layer across the Gulf of Mexico and nearly into Texas in a single day. Confidence in these results is enhanced by the two independent balloons, by the uniformity of the wind fields, and by the three C-130 intercepts with the balloon-based trajectories, all of which had elevated levels of urban tracers.

In addition, the high-altitude transport pathway is consistent with C-130 observations of aerosols over the Gulf of Mexico that appear to be only one day old (Subramanian et al., 2010). The presence of these thinly coated aerosols was previously thought to be inconsistent with the modelsimulated plume age of $40-50 \mathrm{~h}$. The present work suggests that there are two separate plumes, clearly separated in the vertical, that were confounded in the simulated age histogram. Preliminary Lagrangian model runs using the G1/C-130 aircraft data and trajectories presented here, also appear to be self-consistent (Zaveri et al., 2008). A detailed investigation of the evolution of aerosols and trace gases in the 18-19 March outflow will be presented in a subsequent publication by Zaveri.

An image that emerged early during the MILAGRO campaign was that of the Gulf of Mexico as a stew of pollution that lacked discernable source-receptor relationships. In contrast, our results suggest that thermal stratification and vertical wind shear can decouple the MCMA plume from the terrain, sending it out over the Gulf of Mexico at high altitudes. We find that the plume can retain its identity for at least 24$30 \mathrm{~h}$ and, at the highest altitudes, likely much longer. The role of fine-scale structure in controlling transport poses a challenge to regional models which rely on coarse schemes for vertical mixing and parameterization of the boundary layer. These results therefore make a strong case for further analyzing such features in the model simulations.

The MILAGRO campaign, in addition to its scientific success, reached new milestones in the efficient integration and dissemination of data from a wide array of instruments and platforms. The technology available for collecting, processing, and distributing flight data, in particular, is rapidly evolving due, in part, to the phenomenal growth of Unmanned Aerial Systems (UAS). The CMET balloons share with UAS some of the same challenges of communication, data visualization, and long-distance control. The balloon operations have therefore followed a similar path and can now generate, during flight, imagery like that presented in this paper. This new paradigm of real-time analysis and visualization, now unfolding in many areas of research, has the potential to contribute substantially to atmospheric field experiments in the future.

Acknowledgements. We gratefully acknowledge the support of the National Science Foundation Atmospheric Chemistry Program (Grant Numbers: ATM-0511833, ATM-0810950, and ATM0511803), the National Center for Atmospheric Research (NCAR), the Servicios a la Navegación en el Espacio Aéreo Mexicano (SENEAM), Instituto Nacional de Ecología (INE), pilots and crew of the C-130, José Meitín at NCAR, Sandra I. Ramírez Jiménez at the Centro de Ciencias de la Atmósfera, Universidad Nacional Autónoma de México, and our many gracious hosts in Mexico. The C-130 meteorological data and SABL imagery was provided by NCAR/EOL under sponsorship of the National Science Foundation. All analysis was performed in the Matlab (v7.0.1) programming environment from the MathWorks Inc.

Edited by: L. Molina

\section{References}

Apel, E. C., Hills, A. J., Lueb, R., Zindel, S., Eisele, S., and Riemer, D. D.: A Fast-GC/MS system to measure C2 to C4 carbonyls, and methanol aboard aircraft, J. Geophys. Res., 108, 8794, doi:10.1029/2002JD003199, 2003.

Apel, E. C., Hills, A. J., Flocke, F., Zheng, W., Fried, A., Weibring, P., McKenna, D., Emmons, L., Orlando, J., Karl, T., Campos, T., Riemer, D. D., Atlas, E., Blake, D., Olson, J., Chen, G., Crawford, J., and Sive, B.: Observations of volatile organic compounds downwind of Mexico 20 City during MIRAGE-MEX, Eos Trans. AGU, 88(52), Fall Meet. Suppl., Abstract A41F-02, 2007.

Apel, E. C., Emmons, L. K., Karl, T., Flocke, F., Hills, A. J., Madronich, S., Lee-Taylor, J., Fried, A., Weibring, P., Walega, J., Richter, D., Tie, X., Mauldin, L., Campos, T., Weinheimer, A., Knapp, D., Sive, B., Kleinman, L., Springston, S., Zaveri, R., Ortega, J., Voss, P., Blake, D., Baker, A., Warneke, C., Welsh-Bon, D., de Gouw, J., Zheng, J., Zhang, R., Rudolph, J., Junkermann, W., and Riemer, D. D.: Chemical evolution of volatile organic compounds in the outflow of the Mexico City Metropolitan area, Atmos. Chem. Phys., 10, 2353-2375, doi:10.5194/acp-10-23532010, 2010.

Banta, R. M.: Vertical wind velocities from superpressure balloons: A case study using Eole data, Mon. Weather Rev., 104, 628-640, 1976.

Businger, S., Johnson, R., Katzfey, J., Siems, S. and Wang, Q.: Smart tetroons for Lagrangian air-mass tracking during ACE 1, J. Geophys. Res., 104(D9), 11709-11722, 1999.

Chameides, W. L., Yu, H., Liu, S. C., Bergin, M., Zhou, X., Mearns, L., Gao, W., Kiang, C. S., Saylor, R., Luo, C. Huang, Y. Steiner, A., and Giorgi, F.: A case study of the effect of atmospheric aerosols and regional haze on agriculture: An opportunity to enhance crop yields in China through emission controls?, Proc. Natl. Acad. Sci. (PNAS), 96(24), 13626-13633, 1999.

Crounse, J. D., McKinney, K. A., Kwan, A. J., and Wennberg, P. O.: Measurement of gas-phase hydroperoxides by chemical ionization mass spectrometry, Anal. Chem., 78, 6726-6732, doi:10.1021/ac0604235, 2006.

Crounse, J. D., DeCarlo, P. F., Blake, D. R., Emmons, L. K., Campos, T. L., Apel, E. C., Clarke, A. D., Weinheimer, A. J., McCabe, D. C., Yokelson, R. J., Jimenez, J. L., and Wennberg, P. O.: Biomass burning and urban air pollution over the Central Mexican Plateau, Atmos. Chem. Phys., 9, 4929-4944, doi:10.5194/acp-9-4929-2009, 2009.

de Foy, B., Caetano, E., Magaña, V., Zitácuaro, A., Cárdenas, B., Retama, A., Ramos, R., Molina, L. T., and Molina, M. J.: Mexico 
City basin wind circulation during the MCMA-2003 field campaign, Atmos. Chem. Phys., 5, 2267-2288, doi:10.5194/acp-52267-2005, 2005.

de Foy, B., Varela, J. R., Molina, L. T., and Molina, M. J.: Rapid ventilation of the Mexico City basin and regional fate of the urban plume, Atmos. Chem. Phys., 6, 2321-2335, doi:10.5194/acp-6-2321-2006, 2006.

de Foy, B., Fast, J. D., Paech, S. J., Phillips, D., Walters, J. T., Coulter, R. L., Martin, T. J., Pekour, M. S., Shaw, W. J., Kastendeuch, P. P., Marley, N. A., Retama, A., and Molina, L. T.: Basinscale wind transport during the MILAGRO field campaign and comparison to climatology using cluster analysis, Atmos. Chem. Phys., 8, 1209-1224, doi:10.5194/acp-8-1209-2008, 2008.

de Foy, B., Zavala, M., Bei, N., and Molina, L. T.: Evaluation of WRF mesoscale simulations and particle trajectory analysis for the MILAGRO field campaign, Atmos. Chem. Phys., 9, 44194438, doi:10.5194/acp-9-4419-2009, 2009a.

de Foy, B., Krotkov, N. A., Bei, N., Herndon, S. C., Huey, L. G., Martínez, A.-P., Ruiz-Suárez, L. G., Wood, E. C., Zavala, M., and Molina, L. T.: Hit from both sides: tracking industrial and volcanic plumes in Mexico City with surface measurements and $\mathrm{OMI} \mathrm{SO}_{2}$ retrievals during the MILAGRO field campaign, Atmos. Chem. Phys., 9, 9599-9617, doi:10.5194/acp-9-9599-2009, 2009b.

de Lourdes de Bauer, M. and Hernandez-Tejeda, T.: A review of ozone-induced effects on the forests of central Mexico, Environmental Pollution, Air Pollution and Climate Change: A Global Overview of the Effects on Forest Vegetation, 147(3), 2007.

Dockery, D. W., Pope, C. A. III, Xu, X., Spengler, J. D., Ware, J. H., Fay, M. E., Ferris, B. G., and Speizer, F. E.: An association between air pollution and mortality in six US cities, N. Engl. J. Med., 329(24), 1753-1759, 1993.

Doran, J. C and Zhong, S.: Thermally Driven Gap Winds into the Mexico City Basin, J. Appl. Meteorol., 39(8), 1330-1340, 2000.

Doran, J. C., Barnard, J. C., Arnott, W. P., Cary, R., Coulter, R., Fast, J. D., Kassianov, E. I., Kleinman, L., Laulainen, N. S., Martin, T., Paredes-Miranda, G., Pekour, M. S., Shaw, W. J., Smith, D. F., Springston, S. R., and Yu, X.-Y.: The T1-T2 study: evolution of aerosol properties downwind of Mexico City, Atmos. Chem. Phys., 7, 1585-1598, doi:10.5194/acp-7-1585-2007, 2007.

Doran, J. C., Fast, J. D., Barnard, J. C., Laskin, A., Desyaterik, Y., and Gilles, M. K.: Applications of lagrangian dispersion modeling to the analysis of changes in the specific absorption of elemental carbon, Atmos. Chem. Phys., 8, 1377-1389, doi:10.5194/acp-8-1377-2008, 2008.

Fast, J. D., de Foy, B., Acevedo Rosas, F., Caetano, E., Carmichael, G., Emmons, L., McKenna, D., Mena, M., Skamarock, W., Tie, X., Coulter, R. L., Barnard, J. C., Wiedinmyer, C., and Madronich, S.: A meteorological overview of the MILAGRO field campaigns, Atmos. Chem. Phys., 7, 2233-2257, doi:10.5194/acp-7-2233-2007, 2007.

Felzer, B. S., Cronin, T., Reilly, J. M., Melillo, J. M., and Wang, $\mathrm{X}$.: Impacts of ozone on trees and crops, Impact du changement climatique global sur la qualite de l'air a l'echelle regionale, C. R. Geosci., 339(11-12), 2007.

Gerbig, C., Schmitgen, S., Kley, D., Volz-Thomas, A., Dewey, K., and Haaks, D.: An improved fast-response vacuum-UV resonance fluorescence CO instrument, J. Geophys. Res., 104(D1),
1699-1704, 1999.

Grell, G. A., Dudhia, J., and Stauffer, D. R.: A Description of the Fifth-Generation Penn State/NCAR Mesoscale Model (MM5), available from the National Center for Atmospheric Research, P.O. Box 3000, Boulder, CO 80303, NCAR/TN-398 + 1A, 122 pp., 1993.

Holguín, F., Téllez-Rojo, M. M., Hernández, M., Cortez, M., Chow, J. C., Watson, J. G., Mannino, D., and Romieu, I.: Air pollution and heart rate variability among the elderly in Mexico City, Epidemiology, 14(5), 521-527, 2003.

Jáuregui, E. and Romales, E.: Urban effects on convective precipitation in Mexico City, Atmos. Environ., 30(20), 3383-3389, 1996.

Jáuregui, E. and Luyando, E.: Global radiation attenuation by air pollution and its effects on the thermal climate in Mexico City, Int. J. Climatol., 19, 683-694, 1999.

Jáuregui, E.: El Clima de la Ciudad de México, Publisher Instituto de Geografia - UNAM, ISBN 968-856-819-8 , 129 pp., 2000 (in Spanish).

Johnson, R. S., Businger, S., and Baerman, A.: Lagrangian air-mass tracking with Smart Balloons during ACE-2, Tellus B., 52(2), 321-322, 2000.

Knudsen, B. M. and Carver, G. D.: Accuracy of the isentropic trajectories calculated for the AESOE campaign, Geophys. Res Lett., 21, 1199-1202, 1994.

Lally, V. E.: Superpressure balloons for horizontal soundings of the atmosphere, Rept. No. NCAR-TTN-28, 167, NCAR, Boulder, Colorado, 1967.

Lu, R. and Turko, R. P.: Ozone distributions over the Los Angeles basin: Three-dimensional simulations with the SMOG model, Atmos. Environ., 34(24), 4155-4176, 1999.

Malaterre, P.: Vertical sounding balloons for long duration flights, Adv. Space Res., 14(2), 53-59, 1993.

Mao, H., Talbot, R., Troop, D., Johnson, R., Businger, S., and Thompson, A. M.: Smart Balloon observations over the North Atlantic: $\mathrm{O}_{3}$ data analysis and modeling, J. Geophys. Res., 111, D23S56, doi:10.1029/2005JD006507, 2006.

Molina, L. and Molina, M.: Air Quality in the Mexico MegaCity: An Integrated Assessment, Kluwer Academic Publishers, ISBN 1-4020-0452-4, 2002.

Molina, L. T., Kolb, C. E., de Foy, B., Lamb, B. K., Brune, W. H., Jimenez, J. L., Ramos-Villegas, R., Sarmiento, J., ParamoFigueroa, V. H., Cardenas, B., Gutierrez-Avedoy, V., and Molina, M. J.: Air quality in North America's most populous city overview of the MCMA-2003 campaign, Atmos. Chem. Phys., 7, 2447-2473, doi:10.5194/acp-7-2447-2007, 2007.

Molina, L. T., Madronich, S., Gaffney, J. S., Apel, E., de Foy, B., Fast, J., Ferrare, R., Herndon, S., Jimenez, J. L., Lamb, B., Osornio-Vargas, A. R., Russell, P., Schauer, J. J., Stevens, P. S., and Zavala, M.: An overview of the MILAGRO 2006 campaign: Mexico City emissions and their transport and transformation, Atmos. Chem. Phys. Discuss., 10, 7819-7983, doi:10.5194/acpd-10-7819-2010, 2010.

Mosino Aleman, P. A. and Garcia, E.: The Climate of Mexico, in: Climates of North America, editied by: Bryson, R. A. and Hare, F. K., World Survey of Climatology, Elsevier Scientific Publishing Co., Amsterdam-London-New York, 11(4), 345-404, 1974.

Pope III, C. A., Ezzati, M., and Dockery, D. W.: Fine-Particulate Air Pollution and Life Expectancy in the United States, N. Engl. J. Med., 360(4), 376-386, 2009. 
Raga, G. B. and Raga, A. C.: On the formation of an elevated ozone peak in Mexico City, Atmos. Environ., 34(24), 4097-4102, 2000.

Raga, G. B., Baumgardner, D., Castro, T., Martínez-Arroyo, A., and Navarro-González, R.: Mexico City Air Quality: A Qualitative Review of Gas and Aerosol Measurements (1960-2000), Atmos. Environ., 35, 4041-4058, 2001.

Reilly, J., Paltsev, S., Felzer, B., Wang, X., Kicklighter, D., Melillo, J., Prinn, R., Sarofim, M., Sokolov, A., and Wang, C.: Global economic effects of changes in crops, pasture, and forests due to changing climate, carbon dioxide, and ozone, Energ. Policy, 35(11), 5370-5383, 2007.

Riddle, E. E., Voss, P. B., Stohl, A., Holcomb, D., Maczka, D., Washburn, K., and Talbot, R. W.: Trajectory model validation using newly developed altitude-controlled balloons during the International Consortium for Atmospheric Research on Transport and Transformations 2004 campaign, J. Geophys. Res., 111, D23S57, doi:10.1029/2006JD007456, 2006.

Ridley, B. A., Walega, J. G., Dye, J. E., and Grahek, F. E.: Distributions of $\mathrm{NO}, \mathrm{NO}_{\mathrm{x}}, \mathrm{NO}_{\mathrm{y}}$, and $\mathrm{O}_{3}$ to $12 \mathrm{~km}$ altitude during the summer monsoon season over New Mexico, J. Geophys. Res., 99, 25519-25534, 1994.

Singh, H. B., Brune, W. H., Crawford, J. H., Flocke, F., and Jacob, D. J.: Chemistry and transport of pollution over the Gulf of Mexico and the Pacific: spring 2006 INTEX-B campaign overview and first results, Atmos. Chem. Phys., 9, 2301-2318, doi:10.5194/acp-9-2301-2009, 2009.

Sitch, S., Cox, P. M., and Huntingford, C.: Indirect radiative forcing of climate change through ozone effects on the land-carbon sink, Nature, 448(7155), 791-794, 2007

Skamarock, W. C., Klemp, J. B., Dudhia, J., Gill, D. O., Barker, D. M., Wang, W., and Powers, J. G.: A description of the Advanced Research WRF Version 2. NCAR/TN-468 + STR, 8 pp., 2005

Stohl, A.: Computation, accuracy and applications of trajectories-A review and bibliography, Atmos. Environ., 32, 947-966, 1998.

Stohl, A., Forster, C., Frank, A., Seibert, P., and Wotawa, G.: Technical note: The Lagrangian particle dispersion model FLEXPART version 6.2, Atmos. Chem. Phys., 5, 2461-2474, doi:10.5194/acp-5-2461-2005, 2005.

Stuhl, R. B.: Meteorology for Scientists and Engineers, 2nd Edn., Brooks/Cole Publishers, Pacific Grove, CA, 2000.

Subramanian, R., Kok, G. L., Baumgardner, D., Clarke, A., Shinozuka, Y., Campos, T. L., Heizer, C. G., Stephens, B. B., de Foy, B., Voss, P. B., and Zaveri, R. A.: Black carbon over Mexico: the effect of atmospheric transport on mixing state, mass absorption cross-section, and BC/CO ratios, Atmos. Chem. Phys., 10, 219-237, doi:10.5194/acp-10-219-2010, 2010.

Voss, P. B., Riddle, E. E., and Smith, M. S.: Altitude control of longduration balloons, AIAA J. of Aircraft, 42(2), 478-482, 2005.
Voss, P. B.: Advances in Controlled Meteorological (CMET) balloon systems, Proceedings of the 20th AIAA Aerodynamic Decelerator Systems Technology Conference and Seminar and 18th AIAA Lighter-Than-Air Systems Technology conference and AIAA Balloons Systems conference,(AIAA-2009-164928), Seattle, Washington, 4-7 May, 2009.

Whiteman, C. D., Zhong, S., Bian, X., Fast, J. D., and Doran, J. C.: Boundary layer evolution and regional-scale diurnal circulations over the Mexican plateau, J. Geophys. Res., 105(D8), 1008110102, 2000

Yokelson, R. J., Urbanski, S. P., Atlas, E. L., Toohey, D. W., Alvarado, E. C., Crounse, J. D., Wennberg, P. O., Fisher, M. E., Wold, C. E., Campos, T. L., Adachi, K., Buseck, P. R., and Hao, W. M.: Emissions from forest fires near Mexico City, Atmos. Chem. Phys., 7, 5569-5584, doi:10.5194/acp-7-5569-2007, 2007.

Zak, B. D.: Lagrangian studies of atmospheric pollutant transformations, in: Trace Atmospheric Constituents: Properties, Transformations, Fates, edited by: Nriagu J. O., John Wiley \& Sons, 303-344, 1983.

Zaveri, R. A., Alexander, M. L., Ortega, J., Fast, J. D., Hubbe, J., Voss, P., Canagaratna, M., Onasch, T. B., Jayne, J. T., Worsnop, D. R., Kleinman, L. I., Springston, S. R., Daum, P. H., DeCarlo, P., Jimenez, J. L., Campos, T., Flocke, F., Knapp, D., Montzka, D., Weinheimer, A., Zheng, W., Hodzic, A., and Madronich, S.: Evolution of Trace Gases and Aerosols in the Mexico City Pollution Outflow during a Long Range Transport Event, Proceedings of the American Association for Aerosol Research 27th Annual Conference, Orlando, Florida, 21-24 October, 2008.

Zaveri, R. A., Berkowitz, C. M., Brechtel, F. J., Gilles, M. K., Hubbe, J. M., Jayne, J. T., Kleinman, L. I., Laskin, A., Madronich, S., Onasch, T. B., Pekour, M., Springston, S. R., Thornton, J. A., Tivanski, A. V., and Worsnop, D. R.: Nighttime chemical evolution of aerosol and trace gases in a power plant plume: Implications for secondary organic nitrate and organosulfate aerosol formation, $\mathrm{NO}_{3}$ radical chemistry, and $\mathrm{N}_{2} \mathrm{O}_{5}$ heterogeneous hydrolysis, J. Geophys. Res., 115, D12304, doi:10.1029/2009JD013250, 2010a.

Zaveri, R. A., Voss, P. B., Berkowitz, C. M., Fortner, E., Zheng, J., Zhang, R., Valente, R. J., Tanner, R. L., Holcomb, D., Hartley, T. P., and Baran, L.: Overnight atmospheric transport and chemical processing of photochemically aged Houston urban + petrochemical industrial plume, J. Geophys. Res., in review, 2010b. 